\title{
Flexural behavior and ductility of hybrid high performance steel I-girders
}

\author{
Chun-Sheng Wanga, ${ }^{\mathrm{a},}$ Lan Duan ${ }^{\mathrm{a}}$, Y. Frank Chen ${ }^{\mathrm{b}}$, and Shi-Chao Wang ${ }^{\mathrm{a}}$ \\ ${ }^{a}$ Bridge Engineering Research Institute, Highway School, Chang'an University, Xi'an, 710064, China \\ ${ }^{\mathrm{b}}$ Dept. of Civil Engineering, Penn State Harrisburg, 777 W Harrisburg Pike, Middletown, PA 17057, USA
}

\section{Abstract}

The flexural behavior and ductility of high performance steel (HPS) girders were investigated experimentally. Thirteen simply supported I-girders of HPS 485W (nominal yield strength, $\left.f_{y}=485 \mathrm{MPa}\right)$ flanges and webs with different steel grades including Q235 $\left(\mathrm{f}_{\mathrm{y}}=\right.$ 235MPa), Q345 $\left(\mathrm{f}_{\mathrm{y}}=345 \mathrm{MPa}\right)$, and HPS $485 \mathrm{~W}$ were tested. Five additional girders considering different flange strengths of Q345, Q420 $\left(f_{y}=420 \mathrm{MPa}\right)$, and Q500 $\left(f_{y}=500 \mathrm{MPa}\right)$ were tested and compared. The test results show that the effectiveness of lateral braces is mainly influenced by the location and number, which in turn affect the expansion of plastic fields. The slenderness of element (flange or web) is the major factor affecting the flexural capacity and ductility of a girder. As the flange slenderness increases, flange local buckling occurs much earlier during the inelastic loading phase and thus reduces the girder ductility. As the web slenderness increases, the deformation in the inelastic stage decreases. Under the three-point loading, the girder appears not losing its capacity when the local element buckles. While, under the four-point loading, the flange local buckling depends on the unloading stage. When the high-strength HPS $485 \mathrm{~W}$ steel is used for flanges, the web strength is suggested to be no lower than $345 \mathrm{MPa}(\mathrm{Q} 345$ steel). Using the same geometrical dimensions, the ductility of member is decrease with the increasing of flange strength, which is mainly affected by the yield stress to ultimate stress ratio $\left(\sigma_{\mathrm{y}} / \sigma_{\mathrm{u}}\right)$ of steel. Hence, more restrictive slenderness limit appears necessary for structural designs using high-strength steel.

Keywords: high performance steel; I-girder; flexural behavior; ductility; rotation capacity; slenderness.

Corresponding author. Tel.: +86-13991288994; fax:+86-029-82334434.

E-mail address: wcs2000wcs@163.com (Chun-sheng Wang). 


\section{Nomenclature}

The following symbols are used in this paper:

$E=$ elastic modus;

$\sigma_{\mathrm{y}}=$ yield stress of steel;

$\varepsilon_{\mathrm{y}}=$ yield strain of steel;

$\sigma_{\mathrm{u}}=$ ultimate stress of steel;

$v=$ poisson's ratio;

$R=$ rotation capacity;

$\theta_{\mathrm{p}}=$ rotation when the full plastic moment is reached;

$\theta_{\mathrm{u}}=$ rotation when $M_{\mathrm{p}}$ is reached again in the descending part of the moment-rotation

relationship;

$b_{\mathrm{f}}=$ flange width;

$t_{\mathrm{f}}=$ flange thickness;

$h_{\mathrm{w}}=$ web depth;

$t_{\mathrm{w}}=$ web thickness;

$L=$ span length of the girder;

$h=$ the totle height of cross section;

$f_{\mathrm{y}}=$ nominal yield stress;

$f_{\mathrm{yf}}=$ nominal flange yield stress;

$f_{\mathrm{yw}}=$ nominal web yield stress;

$\sigma_{\mathrm{yf}}=$ actual flange yield strength;

$\sigma_{\mathrm{yw}}=$ actual web yield strength;

$E_{\mathrm{f}}=$ flange elastic modulus;

$E_{\mathrm{w}}=$ web elastic modulus;

$D_{\mathrm{cp}}=$ compressive web height; 
$\lambda_{\mathrm{ef}}=$ flange equivalent slenderness;

$\lambda_{\mathrm{ew}}=\mathrm{Web}$ equivalent slenderness;

$\lambda_{\mathrm{f}}=$ flange nominal slenderness;

$\lambda_{\mathrm{w}}=$ web nominal slenderness

$M_{\mathrm{u}}=$ ultimate capacity;

$M_{\mathrm{p}}=$ full plastic capacity of cross-section;

$M_{\mathrm{pw}}=$ full plastic capacity of web;

$M_{\mathrm{pf}}=$ full plastic capacity of flange;

$\Delta_{\mathrm{p}}=$ mid-span displacement as attaining plastic moment;

$\Delta=$ deformation at mid-span section;

$F=$ force;

$F_{\mathrm{y}}=$ force as steel girder yielding;

$F_{\mathrm{p}}=$ force as attaining plastic moment;

$\varphi_{\mathrm{fp}}=$ local buckling curvature;

$\varepsilon_{\mathrm{st}}=$ average hardening strain. 


\section{Introduction}

Utilizing the manufacturing techniques of quenching and tempering (Q\&T) and thermal mechanical control processing (TMCP), the strength of steel can be increased while maintaining at a low carbon content. The so-called "high performance steel" (HPS) has thus been developed and applied to highway bridges. It has high strength as well as the good characteristics of weld ability, fracture toughness, and corrosion resistance. Use of higher strength steel in bridges would result in lighter structures and is an efficient way to save construction materials [1]. The high toughness of HPS increases the resistance of fracture critical members in steel bridges and thus extends the application of HPS bridges under severe climate as defined by American Association of State Highway and Transportation Officials (AASHTO). Additionally, the corrosion resistance of HPS eliminates the need of painting under service conditions. The superior material characteristics of HPS make it an attractive choice for bridge applications and innovative bridge designs [2-4]. During the past two decades, high performance steel has been progressively developed and increasingly used in bridges in many places in the world, especially in the USA and Japan.

The development of HPS began in 1992 in the USA jointly by the Federal Highway Administration, the U.S. Navy, and the American Iron and Steel Institute. HPS 50W $\left(\mathrm{f}_{\mathrm{y}}=\right.$ $345 \mathrm{MPa})$ and HPS 70W $\left(\mathrm{f}_{\mathrm{y}}=485 \mathrm{MPa}\right)$ were developed with improved toughness, weldability, and weather resistance. Hybrid steel girder is generally more economical than a homogenous one as the high strength of steel can be utilized more efficiently. IABSE reported that the HPS bridges built in the U.S. based on hybrid design concept were more cost-effective [5].

In Japan, the application of high strength steel in bridges started earlier in 1960s. The so-called "bridge high-performance steel" (BHS) such as BHS 500W $\left(\mathrm{f}_{\mathrm{y}}=500 \mathrm{MPa}\right)$ and BHS $700 \mathrm{~W}\left(\mathrm{f}_{\mathrm{y}}=700 \mathrm{MPa}\right)$ was developed. Homma discussed the required performance of BHS for achieving economical bridge designs [6]. His study results reveal that the steel weight ratio 
decreases with the increase of steel yield strength and that the fatigue limit state becomes the governing factor when the steel yield strength is above 500MPa. Thus, 500MPa was suggested as the basic yield strength for BHS. Higher strength steel grades such as $680 \mathrm{MPa}$ and $800 \mathrm{MPa}$ were proposed for long-span bridges to carry the significant dead loads. For example, a great amount of 800MPa steel was used in the stiffened trusses of Akashi Kaikyo Bridge, Japan, which is the world's longest suspension bridge [7].

In Europe, high strength steel with $\mathrm{f}_{\mathrm{y}}=460-690 \mathrm{MPa}$ is available for bridge construction. For example, steel grade S460ML has $\mathrm{f}_{\mathrm{y}}=460 \mathrm{MPa}$, easy weldablity, and high toughness. In Canada, researches were conducted to evaluate the fatigue resistance of HPS $485 \mathrm{~W}$. The results show that the crack propagation properties of HPS are similar to the conventional steel. However, the HPS 485W base material displays higher fatigue endurance limit [8]. Based on their test results, a fatigue life prediction method was proposed for the typical HPS welding details [9].

In China, great efforts were devoted to improve the steel material and the performance of steel bridges. High performance steel Q420q $\left(f_{y}=420 M P a\right), Q 460 q\left(f_{y}=460 M P a\right)$ and Q500q $\left(f_{y}=500 \mathrm{MPa}\right)$ were added in China's steel bridge design specifications [10]. In recent decade, the extremely-low carbon bainite steel production technology was adopted to produce a series of HPS including Q345qE(NH), Q370qE(NH), Q420qE(NH), Q500qE(NH), and Q690qE(NH), in which the number trailing the symbol "q" denotes a steel intended for bridges, "E" means toughness and quality grade, and "NH" indicates weather resistant. They all have the desirable characteristics of HPS described above. For examples, approximately 6300 tons of Q420qE steel were used to fabricate the main steel truss of Chaotianmen Yangtze Bridge (a arch bridge spanning 552m) in China. Wuyang Steel Factory in China produced A709M-HPS 485W for new Oakland Bay Bridge in the U.S. [11]. Anshan Iron and Steel Group Corporation (China) supplied about 84 tons of Q500qDNH for Meixian No.2 steel I-girder bridge in Mei 
country, Shaanxi Province, China. In China, Q345q grade has been most widely used and higher strength steel is normally used for localized or complicated stress components only.

The purpose of HPS exploitation was to construct more efficient bridges with lower carbon release, easier fabrication, higher toughness, and better corrosion resistance, as compared with conventional steel [12]. However, higher strength steel should be used with care since it often results in lighter members that may be restricted due to lateral instability, local buckling, and deflection [13]. Moreover, compared with mild steel, HPS has a higher yield ratio, lower strain ductility ratio, and lower initial strain hardening modulus. These material characteristics could result in a reduced supply of structural ductility for welded I-shaped girders. In order to ensure the effective construction of a HPS bridge, greater effort should be devoted to innovative design methodology and concept.

The objective of this paper is to investigate the flexural behavior and ductility of hybrid HPS I-shaped girders experimentally. In this study, the steel grade of web is assumed to be no greater than that of flanges, which is practically true. The performance of HPS $485 \mathrm{~W}$ girder is the main focus of this paper. Different lower steel grades were considered for the web including Q235, Q345, and HPS 485W. In addition, specimens with different flange strength grades of Q345, Q420, and Q500 were comparatively studied, in which Q500 was produced by the microstructure control of extremely-low carbon bainite steel. The experimental studies consist of eighteen simply-supported hybrid I-girders, in which lateral slenderness, cross section slenderness, material matching, and loading conditions were considered. Based on the experimental results, design suggestions are made for high performance steel bridges.

\section{Research Background}

The ductility of a steel girder is defined as a member's ability to deform inelastically while maintaining its intended load carrying capacity after the plastic moment is attained. The ductility of HPS girder decreases with an increasing yield stress. Thus, the ductility of HPS 
girders is the focus of the study as it is a significant factor affecting the safety of a structural system under earthquake conditions. The ductility is measured by the rotation capacity $(R)$ which is determined by $R=\left\{\left(\theta_{\mathrm{u}} / \theta_{\mathrm{p}}\right)-1\right\}$, where $\theta_{\mathrm{p}}$ is the rotation when the full plastic moment $\left(M_{\mathrm{p}}\right)$ is reached in the ascending part of the moment-rotation relationship and $\theta_{\mathrm{u}}$ is the rotation when $M_{\mathrm{p}}$ is reached again in the descending part of the relationship [14]. It is assumed in the plastic design of framed steel structures that the flexural members have sufficient inelastic deformation capacity while maintaining a level at or above $M_{\mathrm{p}}$. AASHTO and AISC require that a compact member should have a rotation capacity of at least three (i.e., $R \geq 3$ ) for non-seismic regions and $R=7-9$ for seismic regions [15-16]. To achieve a reasonable level of structural ductility for hybrid members and economical designs, plastic analysis would be required.

The stress distribution for a hybrid specimen is shown in Fig. 1. Learned from the previous research [17], stress is linearly distributed along the section depth at initial loading phase, which is same as homogenous specimens. Interestingly, the first yielding occurs at the farthest web location away from the neutral axis for hybrid specimens, while it happens on the outmost fiber of the entire cross section for homogenous specimens. As the load is increased, for hybrid specimens with lower strength for the web the yielding field is expanded from the web to the flange. For homogenous specimens, the yielding spreads from the outmost fiber of the cross section to the neutral axis gradually. The corresponding $M_{\mathrm{p}}$ is expressed by Eq. (1).

$$
M_{\mathrm{p}}=M_{\mathrm{pw}}+M_{\mathrm{pf}}=(1 / 4) t_{\mathrm{w}} h_{\mathrm{w}}^{2} \sigma_{\mathrm{yw}}+t_{\mathrm{f}} b_{\mathrm{f}}\left(h_{\mathrm{w}}+t_{\mathrm{f}}\right) \sigma_{\mathrm{yf}}
$$

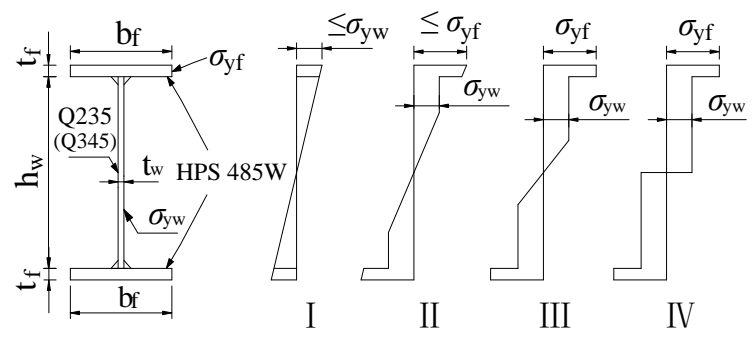

Fig. 1. Stress distribution of a hybrid specimen. 
Schilling and Barth tested simply-supported I-shape girders with different cross-section slenderness ratios [18-19]. All the specimens were set up to simulate the condition of negative flexure at the interior piers of a continuous bridge. The test results indicated that all specimens failed in flange local buckling, web local buckling, and lateral torsional buckling.

Sause and Fahnestock tested I-girders of HPS 100W to study their flexural behavior and ductility [20]. The specimens were tested to failure under the three-point loading condition. Their experimental results demonstrated that the AASHTO LRFD Specifications (1998) were applicable to HPS 100W I-girders in negative moment regions [21]. Salem and Sause conducted additional tests and performed finite element analysis to study the flexural behavior of HPS 100W I-girders [22].

Yakel et al. conducted the flexural tests for four simply-supported homogenous steel I-girders [23]. The first pair of specimens are made of made of HPS 70W $\left(f_{y}=485 \mathrm{MPa}\right)$ steel in which all flanges are compact. While, one web is compact and another is noncompact. For the second pair of specimens, both the flanges and the webs are noncompact. One specimen is made of HPS 70W steel and the other ASTM A572 Grade 50 steel $\left(f_{y}=345 \mathrm{MPa}\right)$ for comparison purposes. The test results showed that the first pair of specimens could reach beyond $M_{\mathrm{p}}$. While the second pair of specimens (noncompact sections) might attain the yield moment $\left(M_{\mathrm{y}}\right)$ but could not reach $M_{\mathrm{p}}$. The test results also indicated that HPS 70W and Grade 50 specimen behaved similarly.

Joo et al. conducted the bending ductility analysis for high strength steel HSB800 (yield strength $=690 \mathrm{MPa}$ and tensile strength $=800 \mathrm{MPa}$ ) I-girders in negative moment regions [24] They proposed an equation to predict the flexural ductility and the measures to improve the ductility.

Frost and Schilling are credited to the early research work on the bending behavior of hybrid steel I-girders [17]. Specifically, they experimentally studied the behavior of hybrid steel 
I-girders with $f_{\mathrm{yf}}$ (nominal flange strength) $=690 \mathrm{MPa}$ and lower web strength considering pure bending and combined bending and shear conditions. Based on the test results, moment-curvature curves were generated to show the typical behavior of hybrid girders. Then, the Joint ASCE-AASHTO Committee on Flexural Members contributed to develop the design method for symmetrical hybrid girders and recognized the efficient utilization of the hybrid design concept [25]. Veljkovic and Johansson analyzed the bending resistance calculation formulas of hybrid steel girders for different cross-section classes according to Eurocode 3 [26-27].

Wang devoted to long life high performance bridge study considering material level, component level, element level and structural levels [28-29]. In material level, strength, toughness, and fatigue and fracture resistance were tested for different steel grades ranging from old steel, Q345 (nominal yield strength 345MPa), Q500 (nominal yield strength 500MPa), and HPS 485W. In component level, fatigue resistance was studied for typical welding HPS connection. In element level, bending behavior and shear behavior of high performance steel girder were studied [30-31]. In structural level, several high performance steel bridge projects are constructed based on a recent study [32]. Three HPS projects were constructed in Shaanxi Province in China. The first project is a three-span I steel girders using HPS in flange and conventional steel Q345 in web, the second project is a composite girder with high performance concrete filled rectangular steel flange and HPS adopted in the bottom flange, and the third project is a steel arch bridge using Q500 steel tube arch infilled with concrete.

Wang devoted to long-life high performance bridge study considering material, component, element, and structural levels [28-29]. In material level, strength, toughness, and fatigue and fracture resistance were tested for different steel grades ranging from old steel, Q345 (nominal yield strength $345 \mathrm{MPa}$ ), Q500 (nominal yield strength 500MPa), and HPS 485W. In component level, fatigue resistance was studied for typical welded HPS connections. In 
element level, bending and shear behaviors of high performance steel girders were studied [30-31]. In structural level, several high performance steel bridges were constructed [32], including three HPS bridges in Shaanxi Province in China. The first constructed bridge is a three steel I-girders using HPS in the flanges and conventional steel Q345 in the web, the second is a composite girder with HPS bottom flange and rectangular top flange filled with high performance concrete, and the third is a steel arch bridge using Q500 steel tube arch infilled with concrete.

Based on the available research results, it can be stated that the major factors affecting the structural ductility as quantified by plastic hinge rotation capacity are flange slenderness, web slenderness, and unbraced length. This study extends the previous research work on HPS by considering noncompact and hybrid girder sections. The results drawn from this study may serve as the basis for the optimal design of high performance steel bridges.

\section{The Experimental Program}

The experimental work includes: (i) the design of eighteen test girders considering different lateral supports, cross-sectional geometry, material matching, and loading methods; (ii) the material tension coupon testing conducted for Q345, Q500, and HPS 485W steel to acquire the actual material properties for the calculation of resistance properties for each test specimen; and (iii) the introduction of loading equipment.

\subsection{Description of Test Specimens}

Thirteen symmetrical welded I-girders made of hybrid HPS were tested to study their flexural behavior and ductility. The three-point loading was applied at the mid-span for specimens 1 to 9 to simulating the negative moment region of a continuous bridge, while the four-point loading was employed at two opposite points close to the mid-span (within $600 \mathrm{~mm}$ from the mid-span) for specimens 10 to 13 to generate the uniform moment distribution. Lateral bracing is an important factor affecting the bending behavior and failure of test girders. Various lateral support locations were considered in the bending test, as shown in Fig. 2 where 
$b_{\mathrm{f}}$ and $t_{\mathrm{f}}$ are the flange width and flange thickness respectively, $h_{\mathrm{w}}$ and $t_{\mathrm{w}}$ are the web depth and web thickness respectively, and $h$ is the totle height of cross section and $L$ is span length of specimen respectively. Specimen 2 has no lateral bracing at all to simulate the steel bridge without concrete deck during the construction stage. As shown in Fig. 2, lateral braces were arranged at quarter span from each end support for specimens 1 and 3 (2 braces for each specimen), while at mid-span, one girder height from the mid-span, and near the end support for specimens 4 to 13 ( 5 braces for each specimen). In all specimens, $12 \mathrm{~mm}$ thick stiffener with nominal yielding strength of $235 \mathrm{MPa}$ were arranged at each supporting section and each loading section. Besides, two pairs of stiffeners were arranged at one girder depth away from mid-span section for specimens 4 to 9 , where the lateral displacement was restrained.

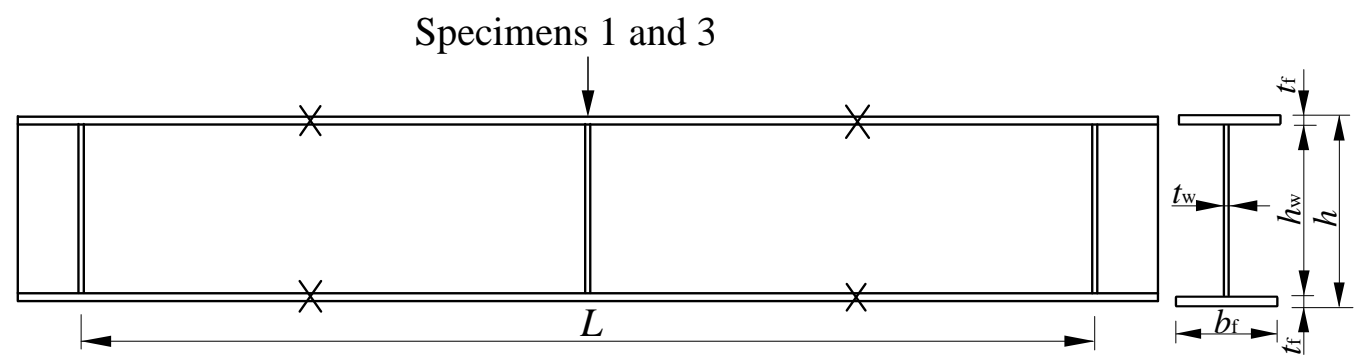

Specimens 4 to 9
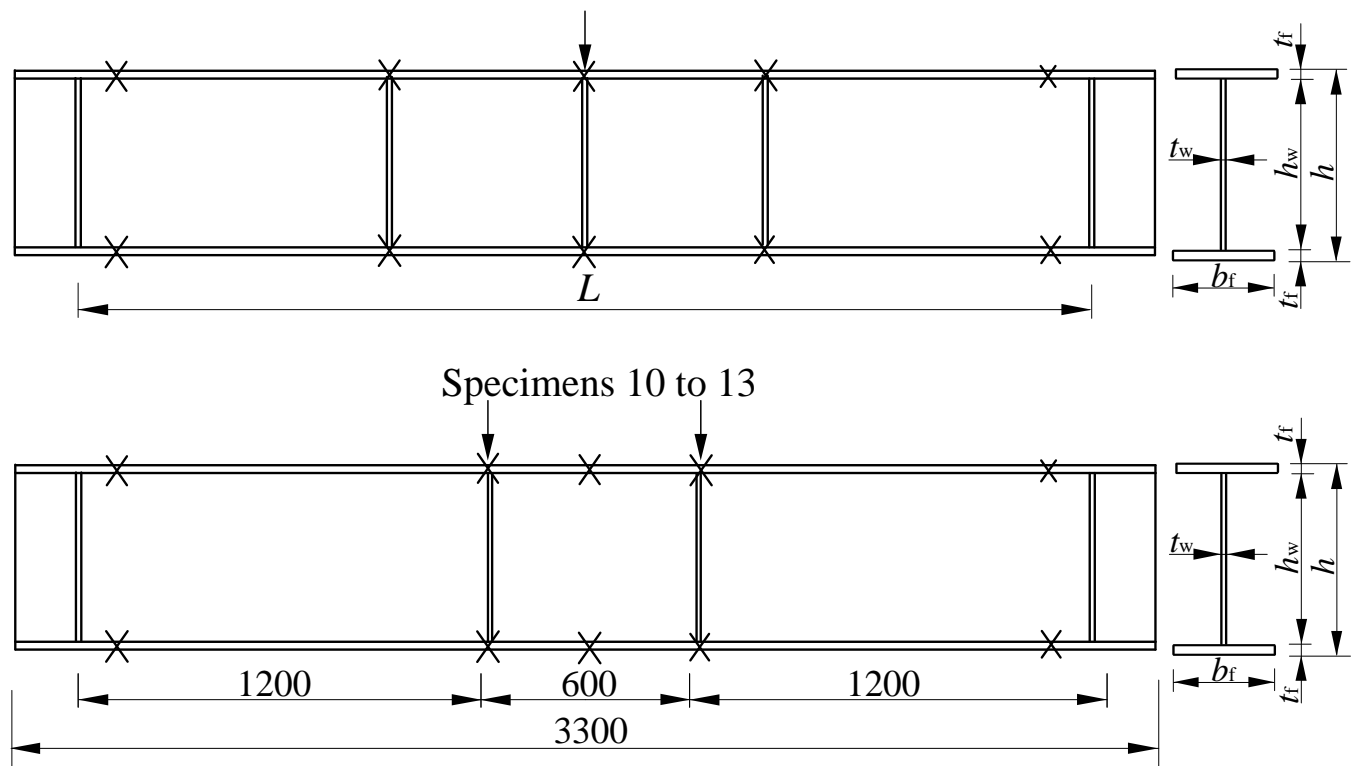

Note: $X$ is the location of lateral bracing

Fig. 2. Lateral support locations for test specimens. 
HPS $485 \mathrm{~W}$ plate with the actual thickness of $13.2 \mathrm{~mm}$ was chosen for all girder flanges, while different steel grades of Q235, Q345, and HPS 485W with the nominal thickness of 8mm were considered for the web. The as-built dimensions for the test girders considering the tolerance of steel plates are presented in Table 1.

\section{Table 1}

As-built dimensions of the test specimens.

\begin{tabular}{ccccccccc}
\hline No. & $\begin{array}{c}b_{\mathrm{f}} \\
(\mathrm{mm})\end{array}$ & $\begin{array}{c}t_{\mathrm{f}} \\
(\mathrm{mm})\end{array}$ & $\begin{array}{c}h_{\mathrm{w}} \\
(\mathrm{mm})\end{array}$ & $\begin{array}{c}t_{\mathrm{w}} \\
(\mathrm{mm})\end{array}$ & $\begin{array}{c}L \\
(\mathrm{~mm})\end{array}$ & Flange & Web & Load Condition \\
\hline 1 & 180 & 13.2 & 250 & 7.5 & 2400 & HPS 485W & Q235 & Three-point \\
2 & 140 & 13.2 & 250 & 7.5 & 2400 & HPS 485W & Q235 & Three-point \\
3 & 140 & 13.2 & 250 & 8.3 & 2400 & HPS 485W & HPS 485W & Three-point \\
4 & 140 & 13.2 & 280 & 7.5 & 3000 & HPS 485W & Q235 & Three-point \\
5 & 130 & 13.2 & 280 & 7.5 & 3000 & HPS 485W & Q235 & Three-point \\
6 & 130 & 13.2 & 350 & 7.5 & 3000 & HPS 485W & Q235 & Three-point \\
7 & 130 & 13.2 & 280 & 8.6 & 3000 & HPS 485W & Q345 & Three-point \\
8 & 220 & 13.2 & 280 & 8.4 & 3000 & HPS 485W & Q345 & Three-point \\
9 & 130 & 13.2 & 280 & 8.3 & 3000 & HPS 485W & HPS 485W & Three-point \\
10 & 130 & 13.2 & 280 & 8.6 & 3000 & HPS 485W & Q345 & Four-point \\
11 & 220 & 13.2 & 280 & 8.6 & 3000 & HPS 485W & Q345 & Four-point \\
12 & 130 & 13.2 & 350 & 8.6 & 3000 & HPS 485W & Q345 & Four-point \\
13 & 130 & 13.2 & 280 & 8.3 & 3000 & HPS 485W & HPS 485W & Four-point \\
\hline
\end{tabular}

$f_{\mathrm{yf}}$ and $f_{\mathrm{yw}}$ represent the nominal flange yield stress and the nominal web yield stress, respectively. From the tension coupon tests, the following material parameters were obtained: actual flange yield strength $\left(\sigma_{\mathrm{yf}}\right)$, actual web yield strength $\left(\sigma_{\mathrm{yw}}\right)$, flange elastic modulus $\left(E_{\mathrm{f}}\right)$, and web elastic modulus $\left(E_{\mathrm{w}}\right)$. Based on these experimentally material properties (Table 2) and AASHTO LRFD (2012), we can determine equivalent flange slenderness ratio $\left(\lambda_{\mathrm{ef}}=\left(b_{\mathrm{f}} / 2 t_{\mathrm{f}}\right)\right.$ $\left.\left(\sigma_{\mathrm{yf}} / f_{\mathrm{yf}}\right)^{0.5}\right)$, nominal flange slenderness ratio $\left(\lambda_{\mathrm{f}}=\left(b_{\mathrm{f}} / 2 t_{\mathrm{f}}\right)\left(\sigma_{\mathrm{yf}} / E_{\mathrm{f}}\right)^{0.5}\right)$, equivalent web slenderness ratio $\left(\lambda_{\mathrm{ew}}=\left(2 D_{\mathrm{cp}} / t_{\mathrm{w}}\right)\left(\sigma_{\mathrm{yw}} / f_{\mathrm{yw}}\right)^{0.5}\right)$, and nominal web slenderness ratio $\left(\lambda_{\mathrm{w}}=\left(2 D_{\mathrm{cp}} / t_{\mathrm{w}}\right)\right.$ $\left.\left(\sigma_{\mathrm{yw}} / E_{\mathrm{w}}\right)^{0.5}\right)$, where $D_{\mathrm{cp}}$ is the depth of compression web equaling to one half of the web height $\left(1 / 2 h_{\mathrm{w}}\right)$ due to the symmetry of cross section.

The calculated material properties, slenderness ratios, and $M_{\mathrm{p}}$ values for the test specimens are summarized in Table 2. 
Table 2

Calculated material properties, slenderness ratios, and $M_{\mathrm{p}}$ values for the test specimens.

\begin{tabular}{cccccccccccc}
\hline Specimen & $\sigma_{\mathrm{yf}}$ & $\begin{array}{c}E_{\mathrm{f}} \\
(\mathrm{GPa})\end{array}$ & $\sigma_{\mathrm{yw}}$ & $E_{\mathrm{w}}(\mathrm{GPa})$ & $b_{\mathrm{f}} / 2 t_{\mathrm{f}}$ & $2 D_{\mathrm{cp}} / t_{\mathrm{w}}$ & $\lambda_{\mathrm{ef}}$ & $\lambda_{\mathrm{ew}}$ & $\lambda_{\mathrm{f}}$ & $\lambda_{\mathrm{w}}$ & $M_{\mathrm{p}}(\mathrm{kN} \times \mathrm{m})$ \\
\hline 1 & 485.3 & 190.7 & 300 & 206.4 & 6.82 & 33.33 & 6.82 & 37.66 & 0.34 & 1.27 & 338.6 \\
2 & 485.3 & 190.7 & 300 & 206.4 & 5.30 & 33.33 & 5.30 & 37.66 & 0.27 & 1.27 & 271.2 \\
3 & 485.3 & 190.7 & 630 & 206.4 & 5.30 & 30.12 & 5.30 & 34.33 & 0.27 & 1.66 & 317.7 \\
4 & 485.3 & 190.7 & 300 & 206.4 & 5.30 & 37.33 & 5.30 & 42.23 & 0.27 & 1.42 & 307.4 \\
5 & 485.3 & 190.7 & 300 & 206.4 & 4.92 & 37.33 & 4.93 & 42.44 & 0.25 & 1.43 & 290.2 \\
6 & 485.3 & 190.7 & 300 & 206.4 & 4.92 & 46.67 & 4.93 & 52.80 & 0.25 & 1.78 & 372.0 \\
7 & 485.3 & 190.7 & 400 & 206.4 & 4.92 & 37.33 & 4.93 & 40.20 & 0.25 & 1.64 & 303.0 \\
8 & 485.3 & 190.7 & 400 & 206.4 & 8.33 & 37.33 & 8.34 & 40.20 & 0.42 & 1.64 & 472.0 \\
9 & 485.3 & 190.7 & 630 & 206.4 & 4.92 & 33.73 & 4.93 & 38.45 & 0.25 & 1.86 & 346.6 \\
10 & 485.3 & 190.7 & 400 & 206.4 & 4.92 & 37.33 & 4.93 & 40.20 & 0.25 & 1.65 & 303.0 \\
11 & 485.3 & 190.7 & 400 & 206.4 & 8.33 & 37.33 & 8.34 & 40.20 & 0.42 & 1.64 & 472.0 \\
12 & 485.3 & 190.7 & 400 & 206.4 & 4.92 & 46.67 & 4.93 & 50.25 & 0.25 & 2.05 & 394.3 \\
13 & 485.3 & 190.7 & 630 & 206.4 & 4.92 & 37.33 & 4.93 & 38.45 & 0.25 & 1.86 & 346.6 \\
\hline
\end{tabular}

AASHTO LRFD (2012) considers compact, noncompact, and slender sections for steel I-girders. Compact sections should satisfy the local buckling requirements of $\lambda_{\mathrm{f}} \leq 0.38, \lambda_{\mathrm{w}} \leq$ 3.76, and $18.7 \lambda_{\mathrm{f}}+\lambda_{\mathrm{w}} \leq 6.25$. For non-compact sections, the slenderness ratios are bound by $0.38<\lambda_{\mathrm{f}} \leq 0.56$ and $3.76<\lambda_{\mathrm{w}} \leq 5.7$. For slender sections, the limiting slenderness ratios will be even greater. Computed slenderness ratios for the test specimens are shown in Fig. 3.

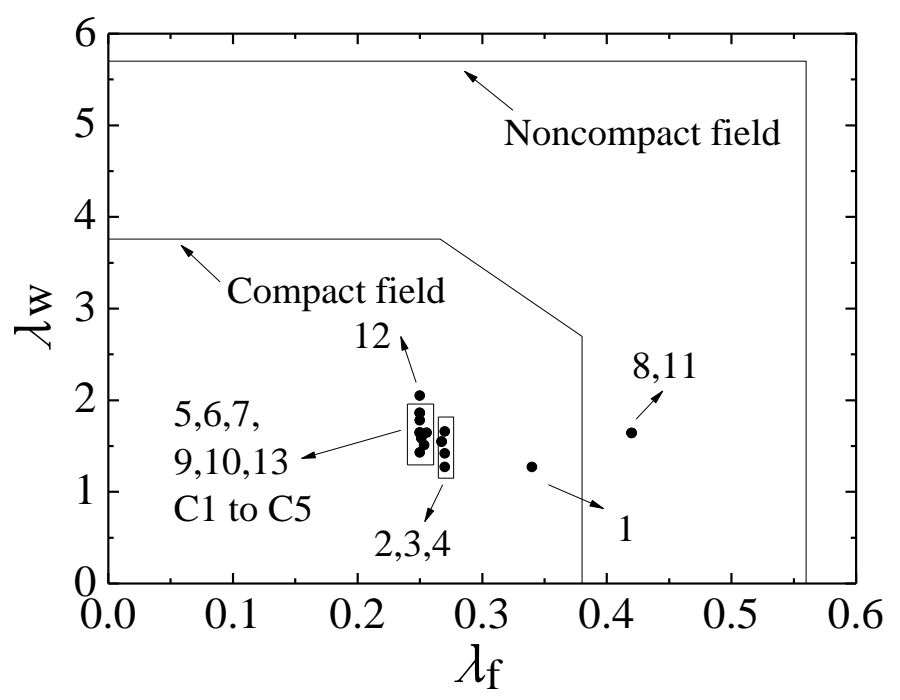

Fig. 3. Computed slenderness ratios of the test specimens. 
For comparisons with HPS 485W test girders, five additional specimens as indicated in Table 3 were tested. Specimen C1 is a homogeneous girder using the traditional Q345 steel, while specimens $\mathrm{C} 2$ to $\mathrm{C} 5$ are the hybrid girders using higher strength steel for the flanges. Specimens $\mathrm{C} 1$ to $\mathrm{C} 5$ belong to compact field according to the computed slenderness ratios.

\section{Table 3}

As-built dimensions for the five additional test specimens.

\begin{tabular}{ccccccccc}
\hline No. & $\begin{array}{c}b_{\mathrm{f}} \\
(\mathrm{mm})\end{array}$ & $\begin{array}{c}t_{\mathrm{f}} \\
(\mathrm{mm})\end{array}$ & $\begin{array}{c}h_{\mathrm{w}} \\
(\mathrm{mm})\end{array}$ & $\begin{array}{c}t_{\mathrm{w}} \\
(\mathrm{mm})\end{array}$ & $\begin{array}{c}L \\
(\mathrm{~mm})\end{array}$ & Flange & Web & Load Condition \\
\hline C1 & 130 & 11.8 & 280 & 7.9 & 3000 & $\mathrm{Q} 345$ & $\mathrm{Q} 345$ & Three-point \\
$\mathrm{C} 2$ & 131 & 12.3 & 280 & 8.2 & 3000 & $\mathrm{Q} 420$ & $\mathrm{Q} 345$ & Three-point \\
C3 & 130 & 12.2 & 280 & 8.4 & 3000 & $\mathrm{Q} 500$ & $\mathrm{Q} 345$ & Three-point \\
C4 & 131 & 12.2 & 280 & 8.6 & 3000 & $\mathrm{Q} 420$ & $\mathrm{Q} 345$ & Four-point \\
C5 & 130 & 12.2 & 280 & 8.4 & 3000 & $\mathrm{Q} 500$ & $\mathrm{Q} 345$ & Four-point \\
\hline
\end{tabular}

\subsection{Tension Testing for Different Steel Grades}

In order to study the material properties of the test specimens, tension coupon tests were conducted for Q345, Q500, and HPS 485W steel. Tensile specimens were designed and cut from steel plates. The primary material characteristics were obtained from the static tensile tests. The strains in both longitudinal and transverse directions were measured by strain gages, which were used to calculate the elastic moduli and Poisson's ratios.

At the conclusion of a test, the stress-strain curve for each specimen was obtained, which was employed in turn to determine the mechanical properties including elastic modulus $(E)$, yield stress $\left(\sigma_{\mathrm{y}}\right)$, yield strain $\left(\varepsilon_{\mathrm{y}}\right)$, ultimate stress $\left(\sigma_{\mathrm{u}}\right)$, and Poisson's ratio $(v)$. The value of $E$ was determined based on the straight line (i.e., the elastic portion) of the stress-strain diagram. To ensure that $E$ was calculated within the elastic range, only the data within $50 \%$ of the mill-certified yield strength were used. $\sigma_{\mathrm{y}}$ was set as the minimum stress in the yielding portion of the stress-strain diagram without considering the initial transient effect. $\sigma_{\mathrm{u}}$ is the maximum stress on the curve. The material properties and stress-strain curves derived from the tensile tests are shown in Table 4 and Fig. 4. 


\section{Table 4}

Tensile test results for different steel grades.

\begin{tabular}{ccccccc}
\hline Steel Grade & Thickness & $E(\mathrm{GPa})$ & $v$ & $\sigma_{\mathrm{y}}(\mathrm{MPa})$ & $0.2 \% \varepsilon y$ & $\sigma_{\mathrm{u}}(\mathrm{MPa})$ \\
\hline Q345 & $8.3 \mathrm{~mm}$ & 193.0 & 0.27 & 415.0 & 0.0041 & 554.0 \\
Q500 & $12.2 \mathrm{~mm}$ & 183.0 & 0.27 & 461.0 & 0.0046 & 782.8 \\
HPS 485W & $13.2 \mathrm{~mm}$ & 190.7 & 0.27 & 485.3 & 0.0046 & 574.1 \\
\hline
\end{tabular}

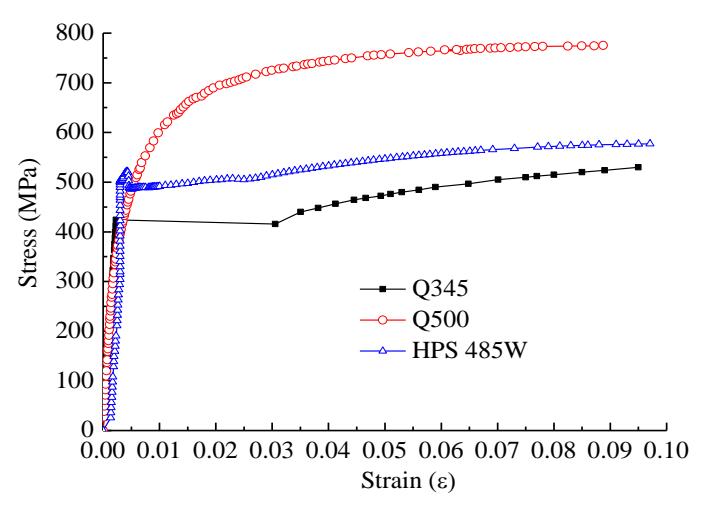

Fig. 4. Stress-strain curves for different steel grades.

Compared to the typical mild steel Q345, the stress-strain curves of HPS 485W and Q500 show higher strength, higher $\sigma_{\mathrm{y}} / \sigma_{\mathrm{u}}$ ratio, decreased elongation, and smaller strain hardening modulus. The curve of HPS 485W displays an obvious yield platform, while not so for Q500.

\subsection{Loading Equipment}

Hydraulic jack with a capacity of 100 tons was used to generate the loads. Load sensors were connected below the jack by bolts to measure loads. For the three-point loading specimens, a steel block with an area of $b_{\mathrm{f}} \times 30 \mathrm{~mm}$ was steadily placed between the specimen and loading sensor at each loading location. For the four-point loading specimens, a loading cross-beam with sufficient rigidity was placed below loading sensor. Each specimen was placed on the reaction pedestals and was simply supported by the $400 \mathrm{~mm}$ diameter rollers at both ends. Although this roller-roller support condition permits the longitudinal displacement of a specimen, the friction at the loading points prevents it.

An equipment with five lateral braces as shown in Fig. 5 was set up to avoid a premature lateral buckling, which consists of anchorage ground girder, triangle reaction frame, horizontal longitudinal girder, and a restrained steel column. A teflon of $5 \mathrm{~mm}$ thick was placed in front of 
the surface of the column and a $2 \mathrm{~mm}$ gap was intentionally reserved between the column and specimen to reduce the friction between the contacting surfaces.

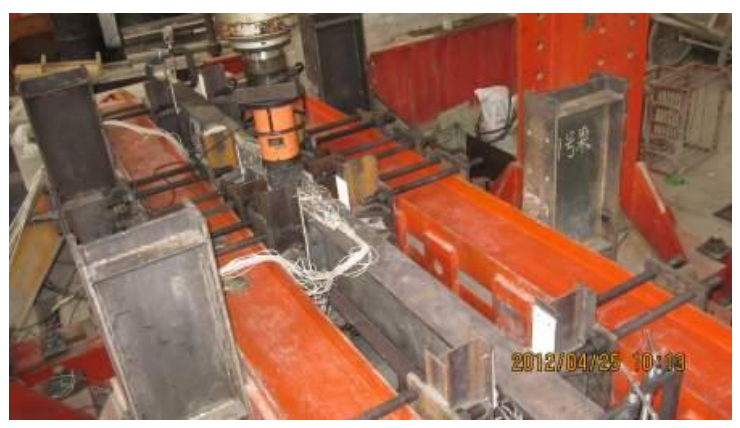

Fig. 5. Lateral bracing equipment.

\section{Result and Discussion}

Each test girder was oriented along the east-west direction and was initially preloaded and unloaded for several times to ensure the normal test condition and eliminate the hysteresis from the strain gauge and displacement measurement panel. Each specimen was then increasingly loaded to fail. At the beginning of a test, a typical load of $20 \mathrm{kN}$ was added in the elastic region. As the material attains the yield strain in the maximum moment section, a load of $10 \mathrm{kN}$ was imposed sequentially with a delay of 1 minute between two subsequent loading steps. Then, in the strain hardening stage the load was further increased by $10 \mathrm{kN}$ sequentially to reach the ultimate capacity. The strain and displacement data were collected continuously. After reaching the maximum capacity, the specimen was unloaded slowly while still undergoing increasing deformation. As the specimen was unloaded to the plastic load $\left(F_{\mathrm{p}}\right)$ level or even lower, a plastic hinge was formed, lateral buckling occurred, and the specimen lost its capacity completely. At this moment, the specimen was totally unloaded and the test was ended. The experimental test results were analyzed considering the major factors affecting the bending behavior.

\subsection{Lateral Bracing}

Different lateral bracing layouts were considered for specimens 1 to 4 , as described in Table 5. Fig. 6 shows $F / F_{\mathrm{p}}-\Delta / \Delta_{\mathrm{p}}$ curves for the test specimens, in which $F_{\mathrm{p}}$ and $\Delta_{\mathrm{p}}$ are the force and 
displacement corresponding to $M_{\mathrm{p}}$, respectively and $F$ and $\Delta$ are the corresponding measured values. As shown in Fig. 6, the deformation increases linearly with the loading prior to yielding for specimens 1 to 4 . Once the mid-span section yields, lateral displacement becomes more noticeable in specimen 2 which has no lateral bracing at all. As the yielding spreads over the section, the lateral displacement becomes even more apparent. When loaded to the plastic load level (i.e., $F / F_{\mathrm{p}}=1$ ), lateral buckling was observed in specimen 2 and the test had to be ended there.

\section{Table 5}

Specimens with different lateral bracing layouts.

\begin{tabular}{cccccccc}
\hline No. & $\begin{array}{c}b_{\mathrm{f}} \\
(\mathrm{mm})\end{array}$ & $\begin{array}{c}t_{\mathrm{f}} \\
(\mathrm{mm})\end{array}$ & $\begin{array}{c}h_{\mathrm{w}} \\
(\mathrm{mm})\end{array}$ & $\begin{array}{c}t_{\mathrm{w}} \\
(\mathrm{mm})\end{array}$ & Flange & Web & $\begin{array}{c}\text { Number of } \\
\text { lateral braces }\end{array}$ \\
\hline 1 & 180 & 13.2 & 250 & 7.5 & HPS 485W & Q235 & Two \\
2 & 140 & 13.2 & 250 & 7.5 & HPS 485W & Q235 & None \\
3 & 140 & 13.2 & 250 & 8.3 & HPS 485W & HPS 485W & Two \\
4 & 140 & 13.2 & 280 & 7.5 & HPS 485W & Q235 & Five \\
\hline
\end{tabular}

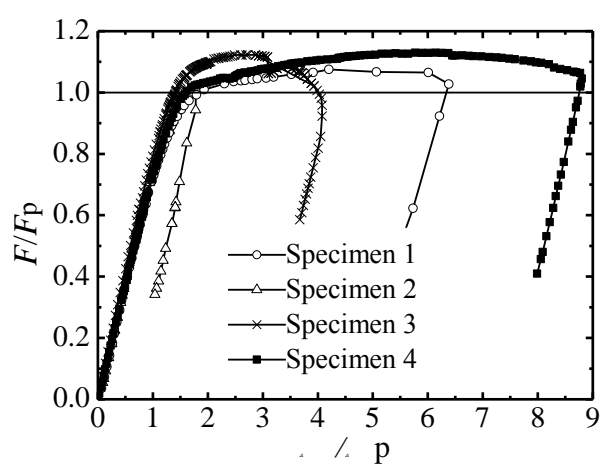

Fig. 6. Load and displacement curves for specimens 1 to 4 .

Compared with specimen 2 (a hybrid girder), when the mid-span section yielded, no lateral buckling phenomenon was noticed in specimens 3 and 4 although the lateral displacement increases with the load. When the load exceeds the plastic value $\left(F>F_{\mathrm{p}}\right)$, for specimen 3 (a homogeneous girder made of HPS $485 \mathrm{~W}$ ) the deflection in mid-span increases significantly with a slight load increase. As the plastic region expands to both sides of mid-span section, the transfer of the lateral forces to the lateral bracing system becomes more apparent progressively. The lateral displacements in the unbraced segments were then observed and the results indicate 
that the lateral bracing system for specimen 3 is not sufficient and lateral buckling failure would occur eventually. The observed failure modes for specimen 3 are local buckling in the compressed flange and lateral buckling near the mid-span. For specimen 4 (also a hybrid girder), the five lateral braces restrain the lateral displacement effectively and the plastic expansion is more complete than specimen 3 (with 2 lateral braces). Plastic hinge was formed in specimen 4, which initiates the failure of the specimen. The observed failure modes for specimen 4 are local buckling in the compressed flange and local buckling in the web near the mid-span.

Similarly, for the other specimens having five lateral braces (i.e., specimens 5 to 13 , Table 2 \& Fig. 2), plastic hinge forms as the plastic region expands progressively during unloading. Eventually, lateral buckling will occur, thus causing the loss of capacity in each specimen as shown in Fig. 7.

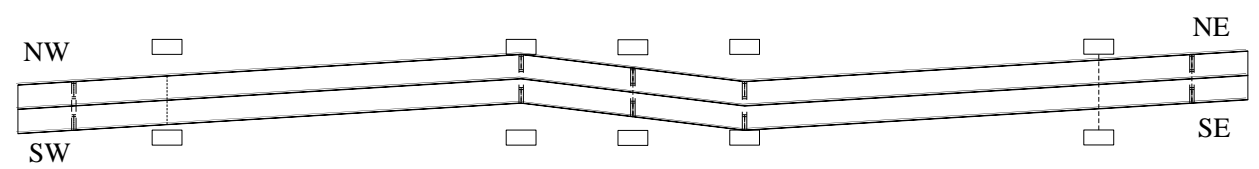

Note: $\square$ means the location of lateral bracing.

Fig. 7. Lateral buckling for specimens 4 to13.

Comparison of the test results shows: (1) The arrangement of lateral braces is critical to the flexural capacity of high-strength welded I-girders; (2) The number of lateral braces influence the effectiveness of lateral supports, which in turn affect the expansion of plastic fields when $F>F_{\mathrm{p}}$; (3) For the three-point loading specimens, the mid-span section and its proximity region are the most effective locations for placing the lateral braces as the lateral displacement occurs first at mid-span; (4) The rigidity of lateral brace is also an important factor affecting the flexural capacity and ductility of high-strength steel I-girders.

Referring to Fig. 6 again, although specimens 1 and 3 have the same lateral bracing pattern, specimen 1 (hybrid girder) has more efficient expansion of plastic region. The failure mode for specimen 1 is local buckling of the compressed flange near the mid-span without apparent 
lateral buckling. This is because the greater flange width in specimen 1 enhances the out-of-plane stiffness to resist the lateral movement. In general, high-strength steel I-girders require different criteria for lateral bracing. For cross sections with greater out-of-plane stiffness, lower requirement is needed for rigidity and lateral bracing. It is suggested that the lateral brace be provided at the section with maximum lateral displacement (such as mid-span section). For cross sections with smaller out-of-plane stiffness, high-strength I-girders will have greater lateral force in the plastic stage. In such cases, the number and rigidity of lateral braces must be ensured, especially at and near the mid-span.

\subsection{Flange Slenderness}

Two pairs of test girders were chosen to analyze the flange slenderness effects, as summarized in Table 6 . The bending test setups for the-three-point loading and the four-point loading are shown in Figs. 8 and 9, respectively.

\section{Table 6}

Specimens with different flange slenderness.

\begin{tabular}{ccccccccc}
\hline No. & $\begin{array}{c}b_{\mathrm{f}} \\
(\mathrm{mm})\end{array}$ & $\begin{array}{c}t_{\mathrm{f}} \\
(\mathrm{mm})\end{array}$ & $\begin{array}{c}h_{\mathrm{w}} \\
(\mathrm{mm})\end{array}$ & $\begin{array}{c}t_{\mathrm{w}} \\
(\mathrm{mm})\end{array}$ & $\begin{array}{c}L \\
(\mathrm{~mm})\end{array}$ & Flange & Web & $\begin{array}{c}\text { Load } \\
\text { Condition }\end{array}$ \\
\hline 7 & 130 & 13.2 & 280 & 8.6 & 3000 & HPS 485W & Q345 & Three-point \\
8 & 220 & 13.2 & 280 & 8.4 & 3000 & HPS 485W & Q345 & Three-point \\
10 & 130 & 13.2 & 280 & 8.6 & 3000 & HPS 485W & Q345 & Four-point \\
11 & 220 & 13.2 & 280 & 8.6 & 3000 & HPS 485W & Q345 & Four-point \\
\hline
\end{tabular}

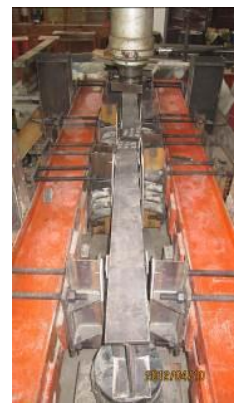

(a) Specimen 7.

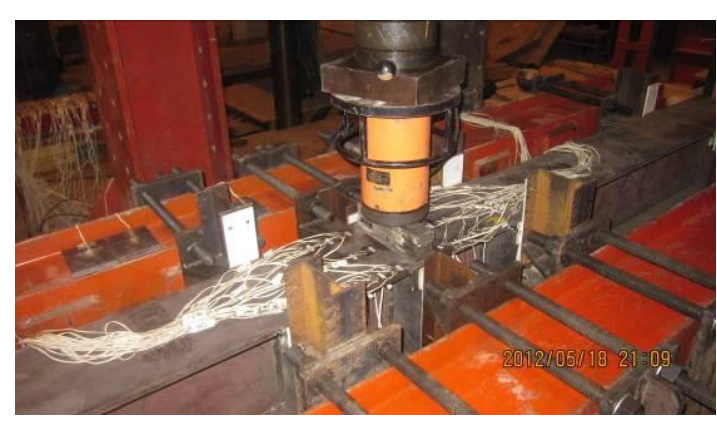

(b) Specimen 8 .

Fig. 8. Bending test setup for the three-point loading (specimens $7 \& 8$ ). 


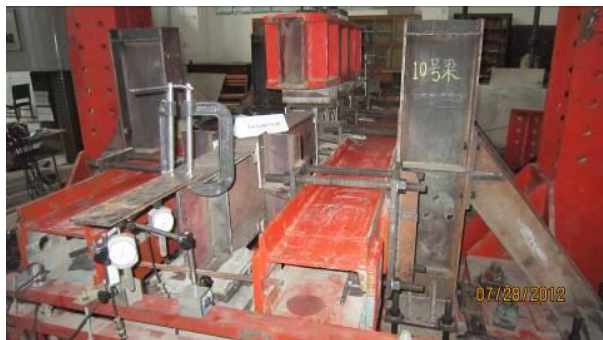

(a) Specimen 10.

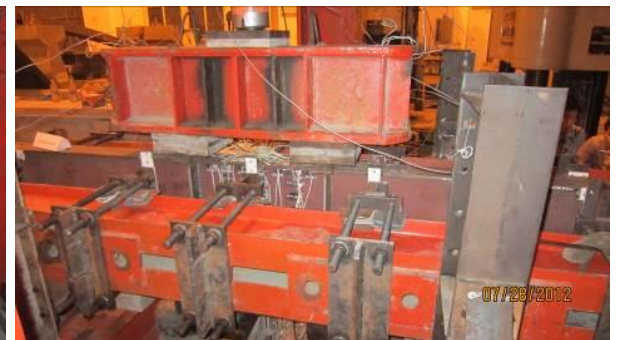

(b)Specimen 11.

Fig. 9. Bending test setup for the four-point loading (specimens $10 \& 11$ ).

The flexural behaviors for specimens $7,8,10$, and 11 are represented by the moment and rotation curves as shown in Fig. 10. As noted, the moment varies with the rotation linearly prior to the flange yielding. By increasing the load, the maximum moment section turns partially plastic and the moment-rotation relationship becomes inelastic. A slight moment increase causes obvious rotation increase until the material attains its ultimate capacity. Then, the specimen was unloaded slowly while the deformation remained advancing. As the specimen was unloaded to the level of $F_{\mathrm{p}}$ or lower, plastic hinge was formed, local buckling was observed, and the specimen lost its capacity completely. As demonstrated in Fig.10, with the increasing flange slenderness the inelastic deformation in the plastic region $\left(M>M_{\mathrm{p}}\right)$ is decreased and the rotation capacity is apparently reduced. This premature flange local buckling triggers the specimen's failure.

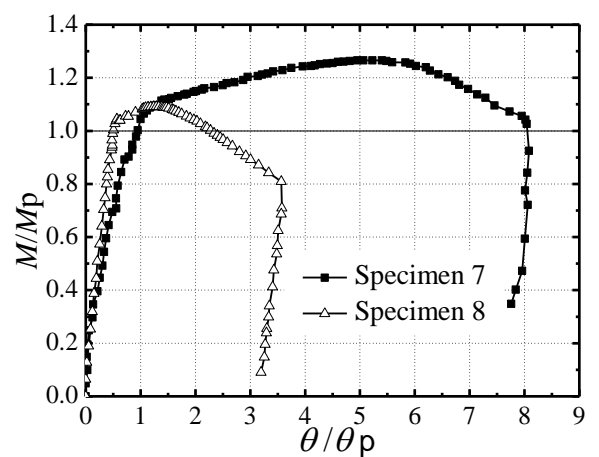

(a) Specimens 7 and 8 .

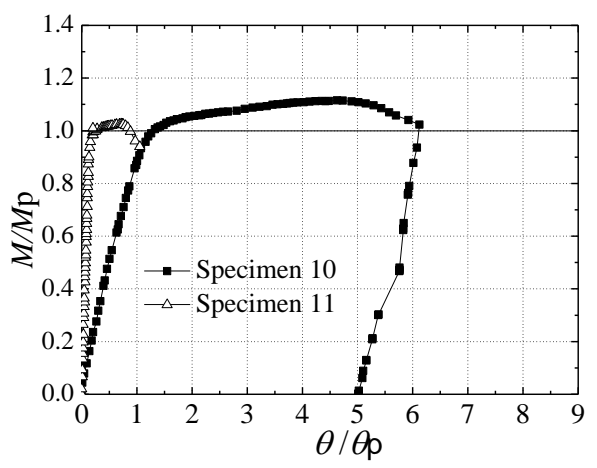

(b) Specimens 10 and 11.

Fig. 10. Moment and rotation curves for the specimens with different flange slenderness.

Failure modes of specimens were observed and analyzed. For specimen 7, Fig. 11(a) shows $38 \mathrm{~mm}$ concave local buckling wave on northeast (NE) flange and $26 \mathrm{~mm}$ convex local buckling wave on southwest (SW) flange. In terms of lateral displacements, $21 \mathrm{~mm}$ displacement 
oriented south on southeast (SE) flange and $12 \mathrm{~mm}$ displacement oriented north on northwest (NW) flange were measured. For specimen 8, shown Fig. 11(b), convex local buckling wave of $55 \mathrm{~mm}$ on NE flange and convex local buckling wave of $71 \mathrm{~mm}$ on SW flange were observed. The measured lateral displacements are $10 \mathrm{~mm}$ to south on SE flange and $13 \mathrm{~mm}$ to north on NW flange. For specimen 10, shown in Fig. 12(a), slightly convex local buckling wave of 4mm on north flange and concave local buckling wave of $24 \mathrm{~mm}$ on south flange in pure bending region were noted. For specimen 11, shown in Fig. 12(b), concave local buckling wave of $104 \mathrm{~mm}$ on north flange and convex local buckling wave of $100 \mathrm{~mm}$ on south flange in pure bending region were observed.

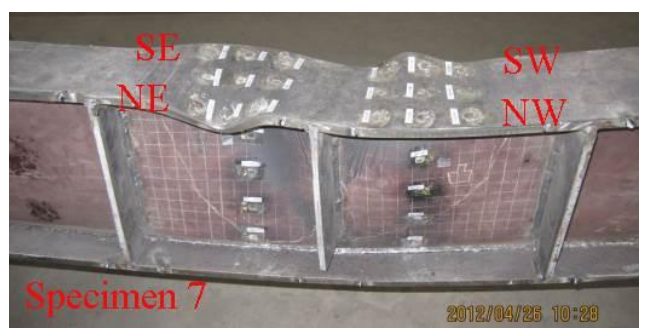

(a) Specimen 7.

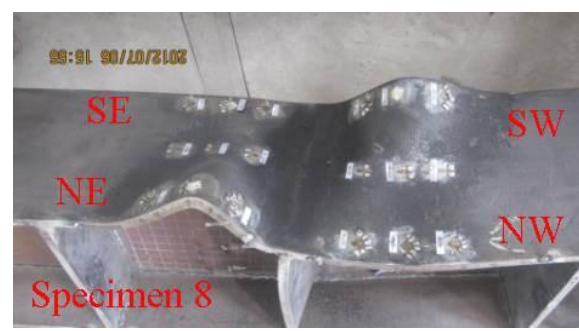

(b) Specimen 8.

Fig. 11. Flange buckling for specimens 7 and 8 .

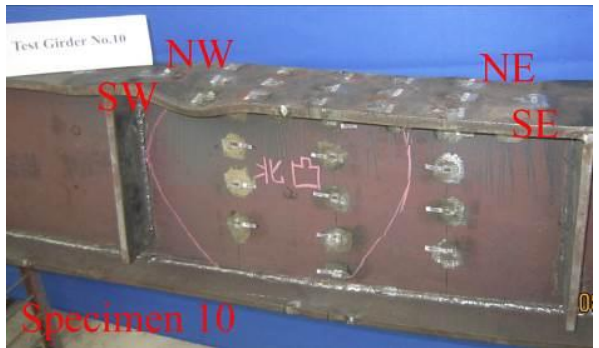

(a) Specimen 10 .

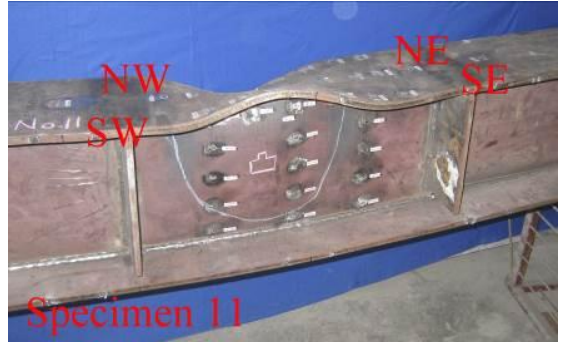

(b) Specimen 11 .

Fig. 12. Flange buckling for specimens 10 and 11.

For the three-point loading case (specimens $7 \& 8$ ), the buckling mode is anti-symmetric about the mid-span. For the four-point loading case (specimens $10 \& 11$ ), convex local buckling waves were found on one side, while concave local buckling waves were observed on another side of the flange in flexural compression. Compared with specimens 8 and 11, the degree of flange local buckling was much smaller in specimens 7 and 10. In other words, the specimen with slender flange has greater flange local buckling wave. With the development of 
flange buckling, the rigidity of specimen is significantly decreased and thus accelerates the expansion of plastic region.

Local buckling curvature $\left(\varphi_{\mathrm{fp}}\right)$ is used to describe the degree of compressive flange buckling during the bending process, which is defined as the difference of strains between the top and bottom surfaces divided by the flange thickness. A positive $\varphi_{\mathrm{fp}}$ value means convex local buckling wave, while a negative $\varphi_{\mathrm{fp}}$ value implies concave one. The curvature was analyzed along each test girder.

Choosing the section at $120 \mathrm{~mm}$ away from the mid-span, the force-compressive flange local buckling curvature $\left(F-\varphi_{\mathrm{fp}}\right)$ curves for test girders 7 and 8 are shown in Fig. 13. As noticed from Fig. 13, $\varphi_{\text {fp }}$ near the mid-span starts increasing after yielding $\left(F>F_{\mathrm{y}}\right)$. When approaching the ultimate capacity $F_{\mathrm{u}}, \varphi_{\mathrm{fp}}$ values increase noticeably on SW and NE flanges and at lesser degree on NW and SE flanges. This implies that local buckling occurs on SW and NE flanges, as agreed with the test results.

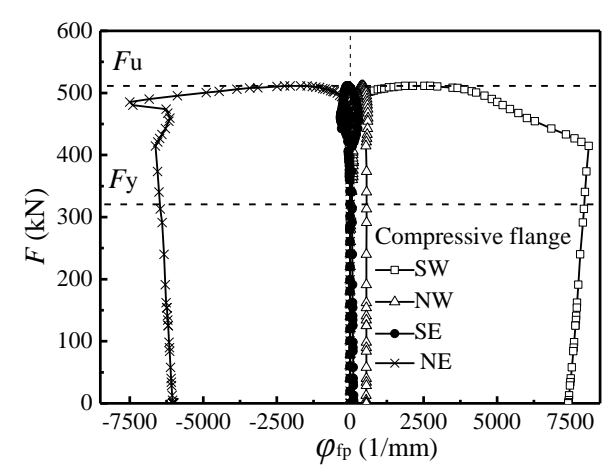

(a) Specimen 7 .

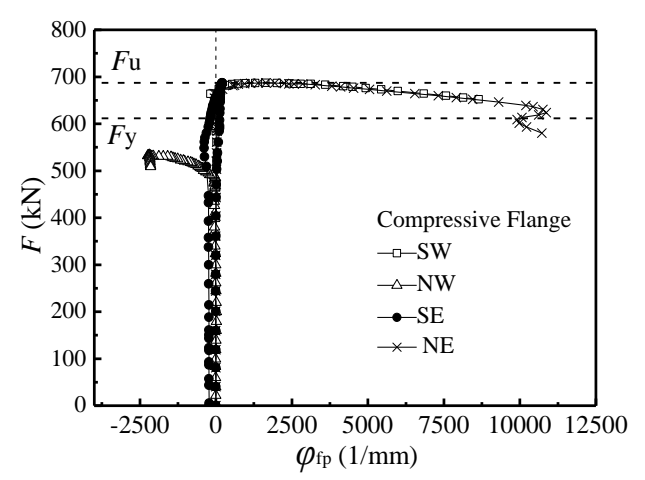

(b) Specimen 8 .

Fig. 13. Load and flange local buckling curvature curves for specimens 7 and 8 .

$F-\varphi_{\text {fp }}$ curves for specimens 10 and 11 are shown in Fig. 14. As shown, $\varphi_{\mathrm{fp}}$ in the pure bending region is near zero before yielding $\left(F<F_{\mathrm{y}}\right)$ and then increases quickly with the increasing load. For specimen 10 , at $160 \mathrm{~mm}$ from the mid-span $\varphi_{\mathrm{fp}}$ value is negative on south side of the flange and positive on the north side. This means that the local buckling curve is concave on the south side of the flange and convex on the north side. For specimen 11, at $60 \mathrm{~mm}$ from the mid-span, the trend for $\varphi_{\mathrm{fp}}$ or the bucking curve is reversed. 


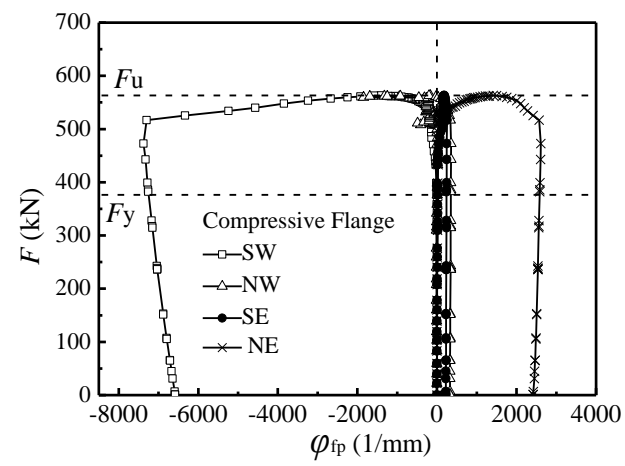

(a) Specimen 10 .

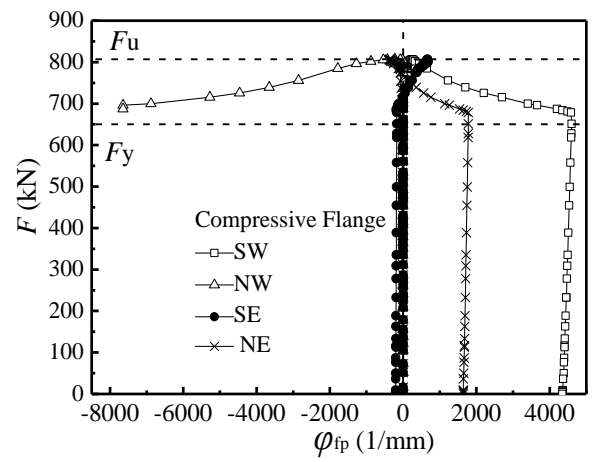

(b) Specimen 11 .

Fig.14. Load and flange local buckling curvature curves for specimens 10 and 11.

\subsection{Web Slenderness}

Two pairs of specimens as listed in Table 7 were chosen to analyze the web slenderness effects. Fig. 15 shows the moment-rotation $\left(M / M_{\mathrm{p}^{-}} \theta\right)$ and force-deformation $(F-\Delta)$ curves for specimens 5 and 6, while Fig. 16 demonstrates them for specimens 10 and 12. These curves were obtained from the bending test results. As seen from the figures, the rotation capacity in the inelastic stage is decreased with the increase of the web slenderness. Due to the existence of initial imperfection, the out-of-plane deformation of web is increasing with the loading. The compressive web buckling near the mid-span was determined based on the measured strains. The web buckling wave continues to increase during the unloading stage until the plastic hinge near the mid-span is formed.

\section{Table 7}

Specimens with different web slenderness.

\begin{tabular}{ccccccccc}
\hline No. & $\begin{array}{c}b_{\mathrm{f}} \\
(\mathrm{mm})\end{array}$ & $\begin{array}{c}t_{\mathrm{f}} \\
(\mathrm{mm})\end{array}$ & $\begin{array}{c}h_{\mathrm{w}} \\
(\mathrm{mm})\end{array}$ & $\begin{array}{c}t_{\mathrm{w}} \\
(\mathrm{mm})\end{array}$ & $\begin{array}{c}L \\
(\mathrm{~mm})\end{array}$ & Flange & Web & Load Condition \\
\hline 5 & 130 & 13.2 & 280 & 7.5 & 3000 & HPS 485W & Q235 & Three-point \\
6 & 130 & 13.2 & 350 & 7.5 & 3000 & HPS 485W & Q235 & Three-point \\
10 & 130 & 13.2 & 280 & 8.6 & 3000 & HPS 485W & Q345 & Four-point \\
12 & 130 & 13.2 & 350 & 8.6 & 3000 & HPS 485W & Q345 & Four-point \\
\hline
\end{tabular}




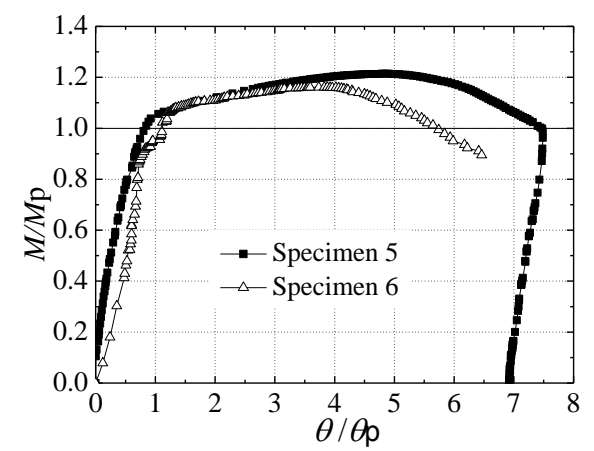

(a) Moment-rotation curves.

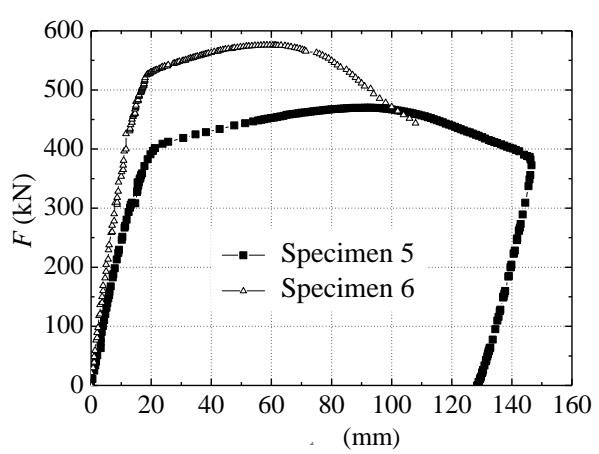

(b) Force-deformation curves.

Fig. 15. Test results for specimens for specimens 5 and 6.

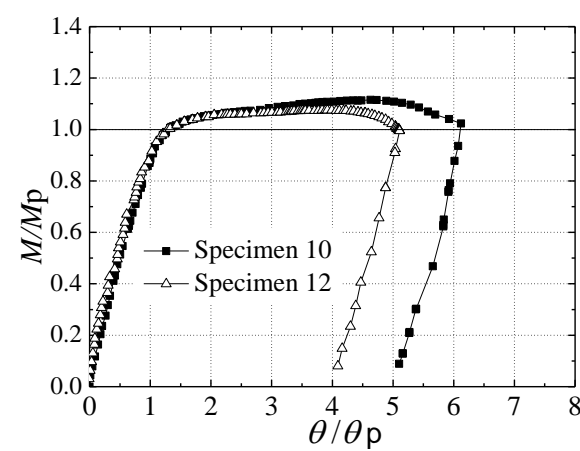

(a) Moment-rotation curves.

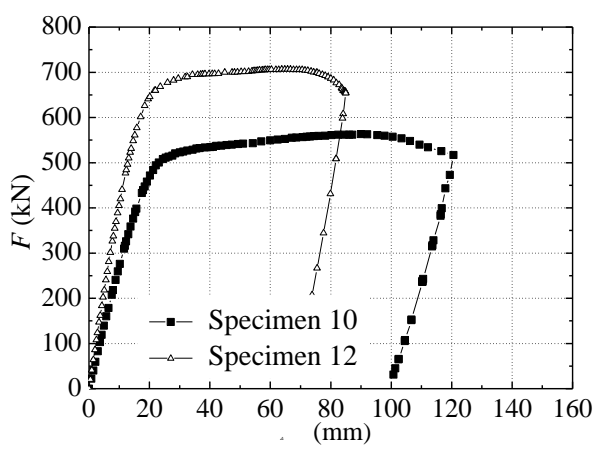

(b) Force-deformation curves.

Fig. 16. Test results for specimens for specimens 10 and 12 .

After the tests, web buckling fields for test girders 5, 6, 10, and 12 were measured, as shown in Figs. 17 to 20. Based on these results, for girders 5 and 6 the west web is convexed to north, while the east web is convexed to south near the mid-span. For girders 10 and 12, bulging of the web to the north was observed in the pure bending region. As a result, the slender the web is, the greater the web buckling field is formed.

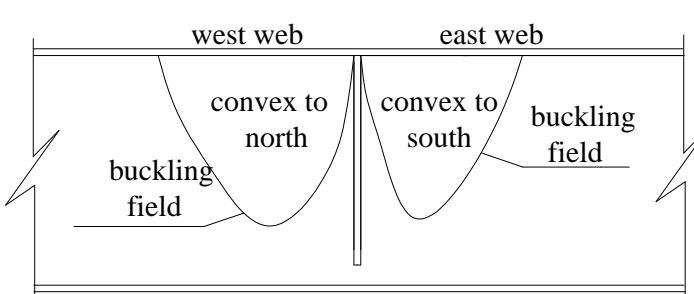

Fig. 17. Web buckling field of specimen 5 .

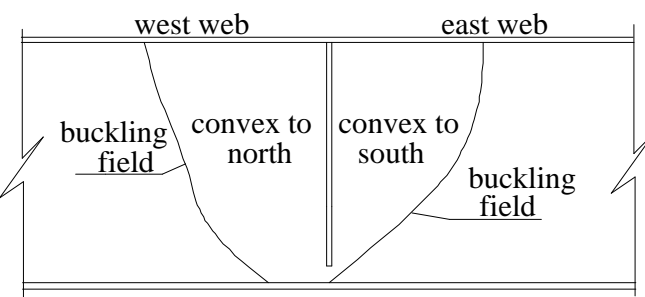

Fig. 18. Web buckling field of specimen 6 . 


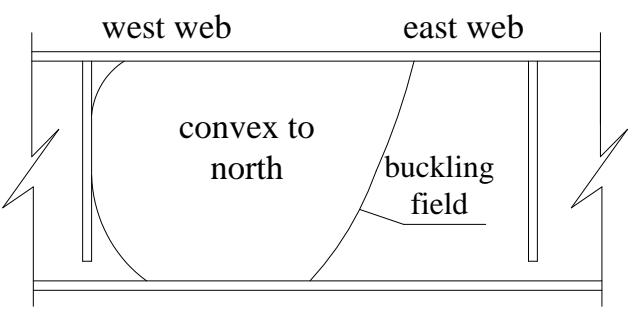

Fig. 19. Web buckling field for specimen 10. Fig. 20. Web buckling field for specimen 12 .

\subsection{Material Matching}

Two sets of test girders, the three-point loading condition (specimens 5, 7, and 9) and the four-point loading condition (specimens 10 and 13) as summarized in Table 8, have similar geometrical dimensions, but different web steel grades were considered to study the material matching effect. Fig. 21 shows the moment-rotation curves after the tests.

\section{Table 8}

Specimens used to study the material matching effect.

\begin{tabular}{ccccccccc}
\hline No. & $\begin{array}{c}b_{\mathrm{f}} \\
(\mathrm{mm})\end{array}$ & $\begin{array}{c}t_{\mathrm{f}} \\
(\mathrm{mm})\end{array}$ & $\begin{array}{c}h_{\mathrm{w}} \\
(\mathrm{mm})\end{array}$ & $\begin{array}{c}t_{\mathrm{w}} \\
(\mathrm{mm})\end{array}$ & $\begin{array}{c}L \\
(\mathrm{~mm})\end{array}$ & Flange & Web & Load Condition \\
\hline 5 & 130 & 13.2 & 280 & 7.5 & 3000 & HPS 485W & Q235 & Three-point \\
7 & 130 & 13.2 & 280 & 8.6 & 3000 & HPS 485W & Q345 & Three-point \\
9 & 130 & 13.2 & 280 & 8.3 & 3000 & HPS 485W & HPS 485W & Three-point \\
10 & 130 & 13.2 & 280 & 8.6 & 3000 & HPS 485W & Q345 & Four-point \\
13 & 130 & 13.2 & 280 & 8.3 & 3000 & HPS 485W & HPS 485W & Four-point \\
\hline
\end{tabular}

As noted from Fig. 21(a), $R$ values for the three-point loading test girders with Q235, Q345, and HPS 485W web (i.e., girders 5, 7, and 9) are 6.47, 7.04, and 7.35, respectively. The corresponding relative bending capacity ratios $\left(M_{\mathrm{u}} / M_{\mathrm{p}}\right)$ are $1.21,1.27$, and 1.24. The respective $R$ values for the four-point loading test specimens (specimens 10 and 13) are 5.12 and 2.94 and the corresponding $M_{\mathrm{u}} / M_{\mathrm{p}}$ ratios are 1.12 and 1.09 (Fig. 21b). High-strength flanges contribute to the bending capacity primarily, while the web strength affects the rotation capacity. When the web strength is increased from $345 \mathrm{MPa}(\mathrm{Q} 345$ steel) to $485 \mathrm{MPa}$ (HPS $485 \mathrm{~W}$ steel), the nominal slenderness ratio of compressive web is increase from 1.65 to 1.7 , initiating web buckling in the inelastic stage. The girder with Q345 web usually displays greater rotation capacity. When the web strength is decreased from $345 \mathrm{MPa}$ to $235 \mathrm{MPa}(\mathrm{Q} 235$ steel), the 
nominal slenderness ratio of compressive web is decrease from 1.65 to 1.43 . At the same time, the yield stress of compressive Q235 web is reduced remarkably. At the onset of plastic moment, buckling will occur in Q235 web earlier, which will dictate the specimen's failure, thus reducing the deformation ability in the inelastic stage. The test results show that rotation capacity does not always increase linearly with the web strength and that an optimal strength combination can be found between flanges and web. When using high-strength HPS 485W for the flanges, it is suggested that lower strength Q345 steel be used for the web in order to make the hybrid girder design more desirable.

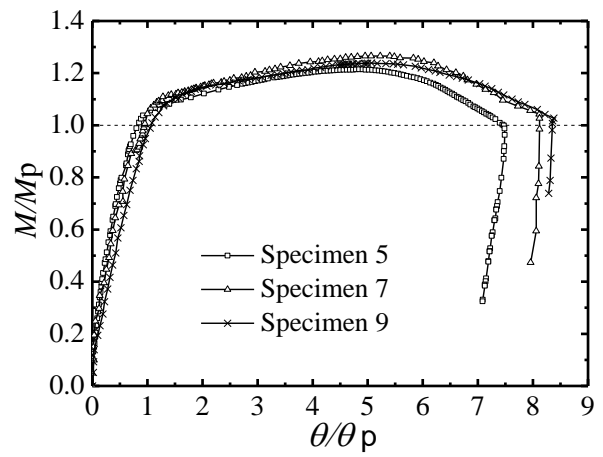

(a) Specimens 5, 7, and 9.

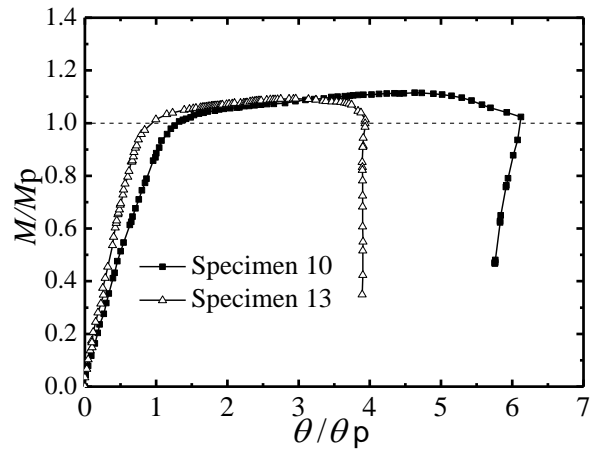

(b) Specimens 10 and 13.

Fig. 21. Moment-rotation curves for the specimens with different web strengths.

Fig. 22 shows the web buckling fields for the specimens with 3 different web strengths. The figure clearly indicates that the web buckling field is different despite of the identical web dimensions. The buckling field for Q345 webs is the largest, while it is the smallest for Q235 webs (Fig. 22). The web buckling field is affected mainly by the inelastic behavior of girder and is essentially proportional to the rotation capacity, $R$.

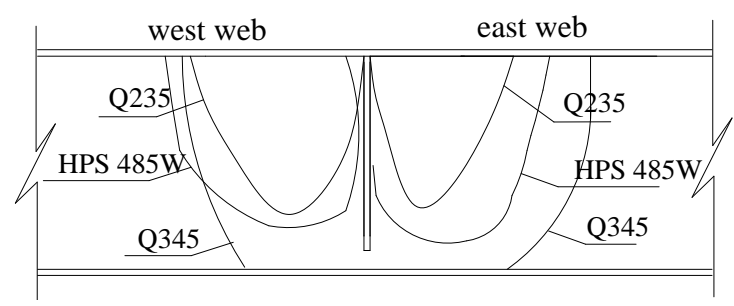

Fig. 22. Web buckling fields after the tests.

\subsection{Loading Conditions}


Both three-point and four-point loading conditions were considered in the flexural tests of high performance steel hybrid girders. The three-point loading condition (Fig. 8) has the load applied at the mid-span of a specimen to simulate the nonuniform moment distribution. The four-point loading condition (Fig. 9) has the loads imposed at two opposite points close to the mid-span (within $600 \mathrm{~mm}$ from the mid-span) to generate the uniform moment distribution. Three pairs of test girders, specimens $7 \& 10$, specimens $8 \& 11$, and specimens $9 \& 13$ as summarized in Table 9, were considered to investigate the effects of loading condition. The moment-rotation and force-deformation relationships for the test girders are shown in Fig. 23 and Fig. 24, respectively.

\section{Table 9}

Specimens used to study the effects of loading condition.

\begin{tabular}{ccccccccc}
\hline No. & $\begin{array}{c}b_{\mathrm{f}} \\
(\mathrm{mm})\end{array}$ & $\begin{array}{c}t_{\mathrm{f}} \\
(\mathrm{mm})\end{array}$ & $\begin{array}{c}h_{\mathrm{w}} \\
(\mathrm{mm})\end{array}$ & $\begin{array}{c}t_{\mathrm{w}} \\
(\mathrm{mm})\end{array}$ & $\begin{array}{c}L \\
(\mathrm{~mm})\end{array}$ & Flange & Web & Load Condition \\
\hline 7 & 130 & 13.2 & 280 & 8.6 & 3000 & HPS 485W & Q345 & Three-point \\
10 & 130 & 13.2 & 280 & 8.6 & 3000 & HPS 485W & Q345 & Four-point \\
8 & 220 & 13.2 & 280 & 8.4 & 3000 & HPS 485W & Q345 & Three-point \\
11 & 220 & 13.2 & 280 & 8.6 & 3000 & HPS 485W & Q345 & Four-point \\
9 & 130 & 13.2 & 280 & 8.3 & 3000 & HPS 485W & HPS 485W & Three-point \\
13 & 130 & 13.2 & 280 & 8.3 & 3000 & HPS 485W & HPS 485W & Four-point \\
\hline
\end{tabular}

The test results shown in Figs. 23 and 24 indicate that the overall flexural behavior is similar between the two loading conditions. For the girders with gradient moment gradient, the yielding field expands continuously from the mid-span to both ends and the moment increases. So, strain hardening begins once the plastic moment is reached. With the increase of yielding, local buckling occurs when a complete buckling wave length is formed in the compressed flange. At this moment, the specimen will not lose its capacity but will decrease its rigidity. When a plastic hinge is formed at the mid-span, the specimen loses its bearing capacity and the lateral torsional buckling follows, triggerring the failure of specimen. For the girders with uniform moment distribution, $M_{\mathrm{p}}$ is maintained until the compressed flange reaches an average hardening strain $\left(\varepsilon_{\mathrm{st}}\right)$ value. Then, the moment will increase beyond $M_{\mathrm{p}}$ as the steel becomes 
hardened. When $M_{\mathrm{p}}$ is reached, the lateral displacement prevails in the unbraced segment due to the effect of initial imperfection. Lateral torsional displacements were observed prior to buckling. Local buckling is expected to occur with the expansion of yielding field to one buckling wave length, signifying the unloading of specimen.

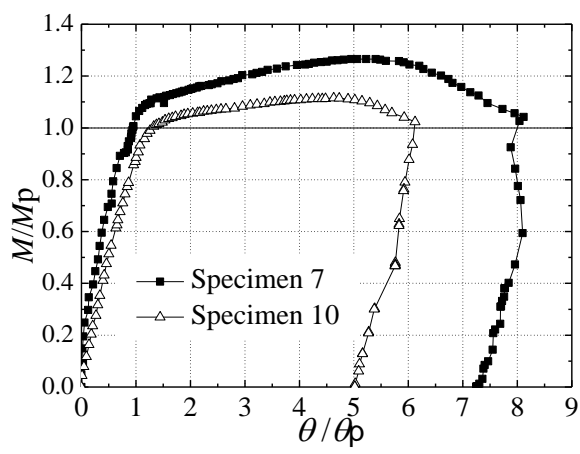

(a) Specimens 7 and 10 .

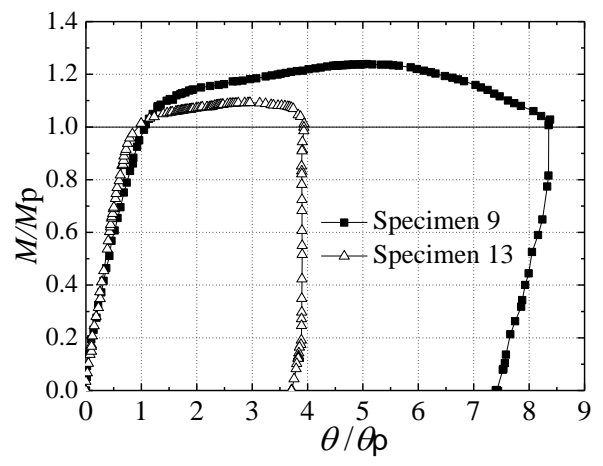

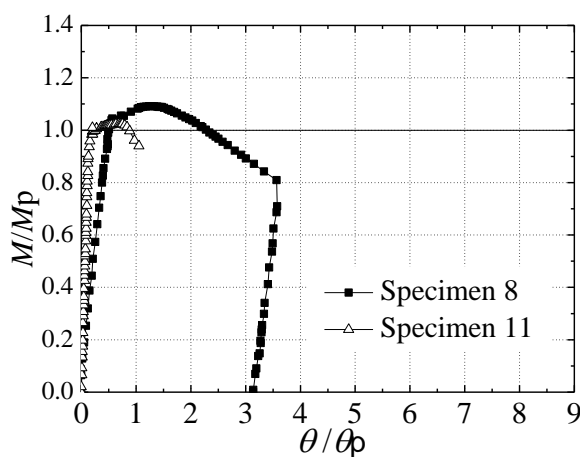

(b) Specimens 8 and 11 .

(c) Specimens 9 and 13.

Fig. 23. Moment-rotation curves for the specimens with three-point loading.

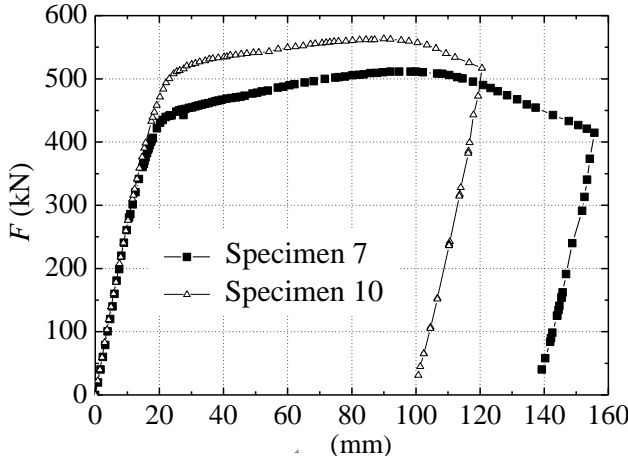

(a) Specimens 7 and 10 .

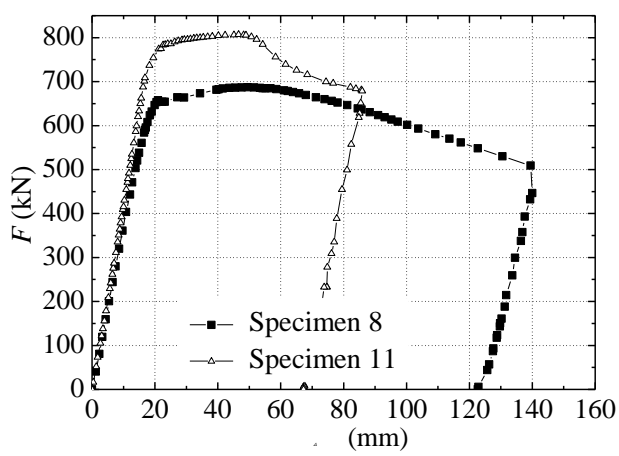

(b) Specimens 8 and 11 . 


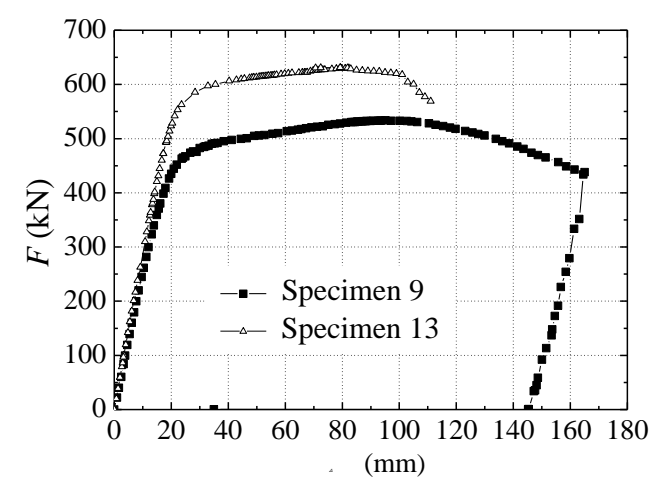

(c) Specimens 9 and 13.

Fig. 24. Displacement-deformation curves for the specimens with four-point loading.

The failure modes for test girders 7, 8, 10, and 11 are shown in Fig. 25. As shown in Fig. 25, local buckling occurs in both compressed flange and compressed web. The local buckling occurs near the mid-span for the girders with the three-point loading condition, while it happens between the two loading points for the four-point loading condition. In the unloading stage after ultimate capacity, compressive flange and web buckling accelerate mid-span stiffener buckling for specimens 7 and 8 . However, for specimens 10 and 11, no buckling was observed in the stiffeners during the whole bending process. The stiffeners in two loading sections serve as effective boundary to limit the expansion of web buckling.

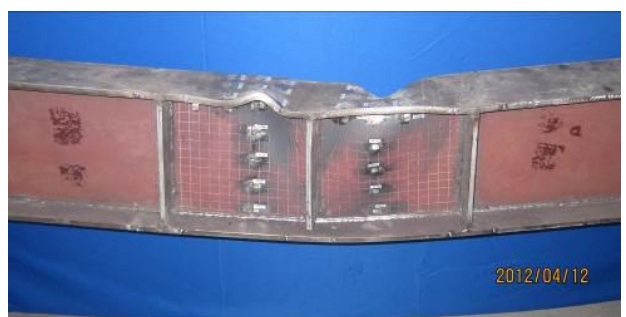

(a) Specimen 7 .

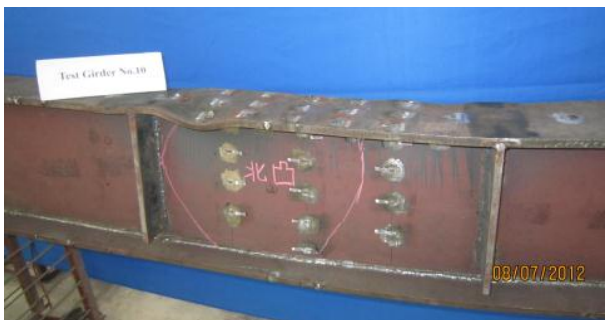

(c) Specimen 10 .

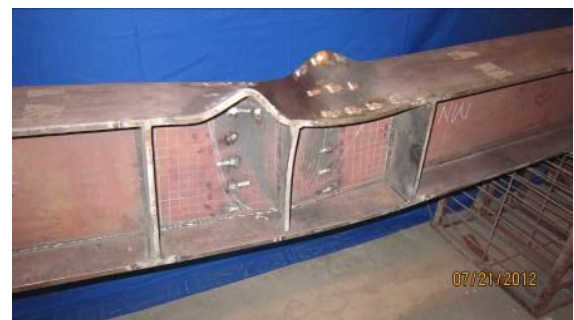

(b) Specimen 8 .

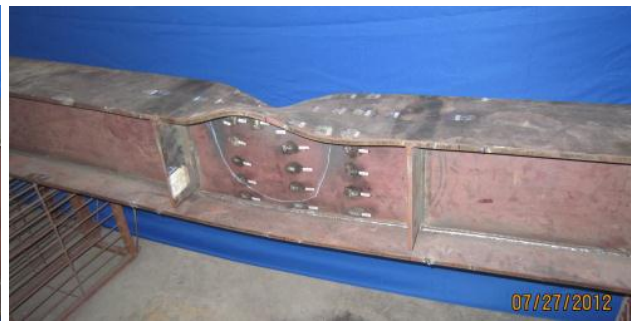

(d) Specimen 11.

Fig. 25. Failure modes of test girders 7, 8, 10, and 11. 
The loading process can also be explained by the yielding of bottom flange. For the test girders under the three-point loading condition, the bottom flange at the mid-span yields first. This yielding field is expanded from the mid-span to both ends as the load increases. The growth of flange strains tends to be symmetric about the mid-span. For the four-point loading condition, the strains are uniformly distributed in the pure bending region. According to the test results, strains at the loading locations are larger and the loads are transferred from the loading points to the pure bending region until the entire region yields. After that, the bottom flange yielding extends to the outer portion of the moment gradient region symmetrically.

\subsection{Flange Strength}

Two sets of test girders, specimens C1, C2, C3 \& 7 (three-point loading) and specimens C4, C5 \& 10 (four-point loading) as listed in Table 10, which have same geometrical dimensions but different flange strength grades, were selected to investigate the material matching effect.

\section{Table 10}

Specimens used to investigate the material matching effect.

\begin{tabular}{ccccccccc}
\hline No. & $\begin{array}{c}b_{\mathrm{f}} \\
(\mathrm{mm})\end{array}$ & $\begin{array}{c}t_{\mathrm{f}} \\
(\mathrm{mm})\end{array}$ & $\begin{array}{c}h_{\mathrm{w}} \\
(\mathrm{mm})\end{array}$ & $\begin{array}{c}t_{\mathrm{w}} \\
(\mathrm{mm})\end{array}$ & $\begin{array}{c}L \\
(\mathrm{~mm})\end{array}$ & Flange & Web & Load condition \\
\hline C1 & 130 & 12.2 & 280 & 8.4 & 3000 & Q345 & Q345 & Three-point \\
C2 & 130 & 12.2 & 280 & 8.4 & 3000 & Q420 & Q345 & Three-point \\
C3 & 130 & 12.2 & 280 & 8.4 & 3000 & Q500 & Q345 & Three-point \\
7 & 130 & 13.2 & 280 & 8.6 & 3000 & HPS 485W & Q345 & Three-point \\
C4 & 130 & 12.2 & 280 & 8.4 & 3000 & Q420 & Q345 & Four-point \\
C5 & 130 & 12.2 & 280 & 8.4 & 3000 & Q500 & Q345 & Four-point \\
10 & 130 & 13.2 & 280 & 8.6 & 3000 & HPS 485W & Q345 & Four-point \\
\hline
\end{tabular}

Fig. 26 shows the moment-rotation curves after the testing. As shown, the inelastic bending behavior differs sigficantly with the flange strength. Specimens with Q345 flanges and Q420 flanges have greater rotation capacity than that of specimens with Q500 and HPS 485W flange. Compared with specimens C3 and C5 with Q500 flanges, specimens with HPS 485W flange (i.e., specimens 7 and 10) have smaller rotation capacity, since HPS 485W shows the greatest yield stress to ultimate stress ratio $\left(\sigma_{\mathrm{y}} / \sigma_{\mathrm{u}}\right)$. 


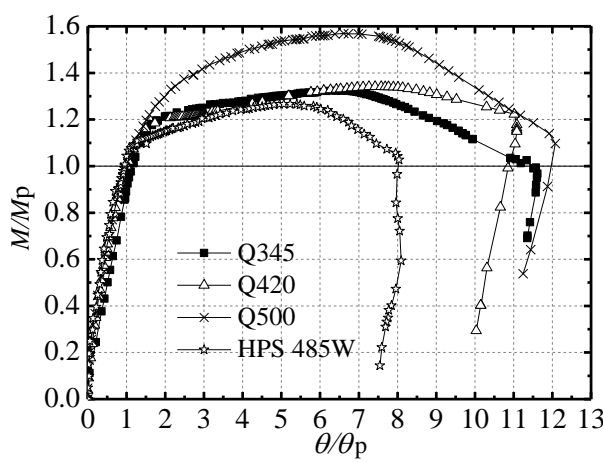

(a) Three-point loading.

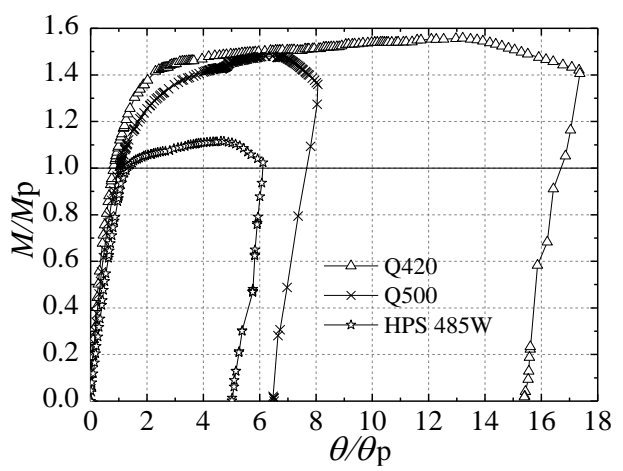

(b) Four-point loading.

Fig. 26. Moment-rotation curves after the tests.

\section{Conclusions}

A number of bending tests were initiated to study the flexural behavior of hybrid steel I-girders made of HPS 485W flanges and different steel grades for the web. Based on the study results, the following conclusions may be drawn:

(1) Slenderness of element (flange or web) is the major factor affecting the flexural capacity and ductility of a girder. With the increase of flange slenderness, the local buckling of compressed flange occurs much earlier and the amplitude of buckling shape is much greater during the inelastic loading phase, thus reducing the ductility. With the increase of the web slenderness, the deformation in the inelastic stage is decreased due to the local buckling of compressed web, thus reducing the rotation capacity.

(2) The test results show that the overall flexural behavior is similar between the three-point loading (nonuniform moment) condition and the four-point loading (uniform moment) condition. For the three-point loading girders (specimens 1-10), buckling will occur when the yielding field stretches to one buckling wave length, but the girder will still remain its capacity. As soon as a plastic hinge is formed at the mid-span, lateral torsional buckling will occur, followed by girder failure. For the four-point loading girders (specimens 11-14), local buckling will occur with the spreading of yielding field signifying the unloading of a specimen. In general, local buckling occurs prior to lateral torsional buckling when girders 
subjected to nonuniform moment distribution, while the opposite is true for girders with uniform moment distribution.

(3) When designing a hybrid high-strength steel I-girder, combination of steel grades between flanges and web can be optimized. If HPS $485 \mathrm{~W}$ is selected for the flanges, Q345 or stronger is suggested for the web.

(4) Lateral braces are necessary for flexural steel girdrs, which can avoid lateral-torsional buckling. The test results indicate that the effectiveness of lateral bracing is significantly influenced by the location and number of lateral braces. The lateral bracing are suggested to be located nearby plastic hinge. For three-point loading girders, mid-span section and its proximity region are the most effective locations for arranging the lateral braces. For the four-point loading girders, pure bending region between two loading section should be effectively restrained by lateral braces.

(5) It is desirable to use the high performance steel in steel bridges to improve the structural performance. However, with the increasing yielding strength the ratio of material yield to ultimate stress increases and the girder ductility decreases. Thus, girder design utilizing high strength steel with yielding strength above $420 \mathrm{MPa}$ should have more restrictive slenderness limits than the conventional steel.

\section{Acknowledgements}

The writers would like to acknowledge the financial support provided by by Ministry of Transport Application Basic Research Project (2014319812080), the Major State Basic Research Development program of China (973 Program) Sub-program (2015CB057703 and 2015CB057706), the National Science Foundation of China (51408056), the Special Fund for

Basic Scientific Research of Central Colleges of the P.R. China, Chang'an University (310821153501, 310821151015), and the steel materials provided by Wuyang Iron and Steel 
Co., Ltd. and Anshan Iron and Steel Group Corporation. However, the opinions expressed in this paper are solely of the authors.

\section{REFERENCES}

[1] Haaijer G. Economy of high strength steel structural members. J. Struct. Div. 1963; 87(8): $1-23$.

[2] Wright W. High performance steel: Research to practice. Public Roads 1997; 60:34-38.

[3] Sause R, Abbas HH, Driver RG. Steel bridge girders with corrugated webs. Proc., FHWA Steel Bridge Conf. for the Western States, NaBRO, Dec., Salt Lake City, UT, 2002; 107-116.

[4] Azizinamini A, Barth K, Dexter R, Rubeiz C. High performance steel: research front-historical account of research activites. J. Bridge Eng. 2004; 9(3): 212-217.

[5] International Association for Bridge and Structural Engineering (IABSE). Use and application of high performance steels for steel structures. Struct. Eng. Doc. 8; 2005.

[6] Homma K, Tanaka M, Matsuoka K, Kasuya T, Kawasaki H. Development of application technologies for bridge high-performance steel, BHS. Nippon Stl. Tech. Rept. No. 97, 2008.

[7] Miki C, Homma K, Tominaga T. High strength and high performance steels and their use in bridge structures. J. Constr. Stl. Res., 2002; 58: 2-10.

[8] Chen H, Grondin GY, Driver RG. Characterization of faitgue properties of ASTM A709 high performance steel. J. Con. Steel Res. 2004; 63: 838-848.

[9] Chen H, Grondin GY, Driver RG. Characterization of faitgue properties of high performance steel. Proc., 1st Intn'l Conf. on Fatigue Damage of Mat., July, Toronto, Canada. 2003.

[10] GB/T 714-2008 (2008). Specification of structural steel for bridge. China Standards Press, Beijing, China. (in Chinese) 
[11] Guo T, Wei M, Liu LX. Development of new type atmospheric corrosion resisting steel A709M- HPS 485W for bridge. J. Stl. Struct., 2009; 24: 17-20 (in Chinese).

[12] Wilson AD. Production of high performance steels for USA bridges, http://www.nabro.unl.edu/articles/20002012/download/wilson.pdf.

[13] Sause R. Barriers to the Use of High Performance Steel in I-Girder Highway Bridges. Struct. Cong., Am. Soc. Civil Engrs., 1996; 108-115.

[14] Yura Joseph A, Galambos, Theodore V, Mayasandra K Ravindra. The bending resistance of steel beams. J. Struct. Div., ASCE, 1978; 104(9): 1355-1370.

[15] AASHTO. AASHTO LRFD bridge design specification. Am. Assoc. State Hwy. \& Transp. Officials, Washington, DC. 2012.

[16] AISC. Load and Resistance factor design specification for structural steel buildings. Am. Instit. Stl. Constr., Chicago, IL. 1999.

[17] Frost RW, Schilling CG. Behavior of hybrid beams subjected to static loads. J. Struct. Div. Am. Soc. Civil Engrs. 1964; 90(3): 55-88.

[18] Barth K E. Moment-rotation characteristics for inelastic design of steel bridge beams and girders. Ph.D. Dissertation, Purdue Univ. West Lafayette, IN. 1996.

[19] Schilling CG, Morcos SS. Moment-rotation tests of steel girders with ultracompact flanges. Rep. on Project 188, Am. Iron \& Stl. Instit., Washingtion, DC, July. 1988.

[20]Sause R, Fahnestock L A. Strength and ductility of HPS-100W I-girders in negative flexure. J. Bridge Eng., Am. Soc. Civil Engrs., 2001; 6(5): 316-323.

[21] AASHTO . AASHTO LRFD bridge design specification. Am. Assoc. State Hwy. \& Transp. Officials, Washington, DC. 1998.

[22] Salem E S, Sause R. Flexural strength and ductility of highway bridges fabricated from HPS-100W steel. ATLSS Rep. No. 04-12, Center for Adv. Tech. Large Struct. Sys., Lehigh Univ., Bethlehem, PA. 2004. 
[23] Yakel A J, Mans P, Azizinamini A. Flexural capacity and ductility of HPS-70W bridge girders. Eng. J., Am. Instit. Stl Constr., 2002; 39: 38-51.

[24] Joo HS, Moon J, Choi BH, Lee H E. Rotation capacity and optimum bracing point of high strength steel I-girders. J. of constr. Stl. Res., 2013; 88: 79-89.

[25] Joint ASCE-AASHO Committee on Flexural Members. Design of hybrid steel beams. Rept. of the subcommittee 1 on beams and girders, J. Struct. Div., Am. Soc. Civil Engrs., 1968; 94(6): 1397-1426.

[26] Veljkovic M., Johansson B. Design of hybrid steel girders. J. Constr. Steel Res., 2004; 60: $535-547$.

[27] Eurocode 3. Design of steel structures. Part 1.1 General rules and rules for buildings. ENV 1993-1-1; 1992.

[28] Wang CS, Duan L, Zheng L, Hu JY. Fatigue crack growth rate tests of high performance steel HPS 485W for bridges. Eng. Mech., 2013a; 30(6): 212-216 (in Chinese).

[29] Wang CS, Duan L, Hu JY, Zheng L. Fracture and toughness test study of high performance steel HPS 485W for bridge engineering. Eng. Mech., 2013b; 30(8): 54-59 (in Chinese).

[30] Wang CS, Duan L, Wang JM, Zheng L. Bending Behavior and Ductility test study of high performance steel beam based on hybrid design. China J. of Highway and Transport, 2012; 25(2): 81-89 (in Chinese)

[31] Duan L, Zhang L, Wang CS, Zheng L. Flexural behavior test of high strength steel I beam. J. of Chang 'an Uni. (Natural Science Edition), 2012; 32(6): 52-58 (in Chinese).

[32] Wang CS, Duan L, Zhu JW, Wang XX. Innovative research of high performance and sustainable steel bridges. Proc. of the Inter. Sym. on Innovation \& Sustainability of Struc. in Civil Eng., Nanjing: Southeast University Press, 2011; 951-956. 